\title{
Artificially generated turbulence: a review of phycological nanocosm, microcosm, and mesocosm experiments
}

\author{
Russell N. Arnott • Mehdi Cherif • Lee D. Bryant • Danielle J. Wain
}

Received: 25 June 2020/Revised: 3 December 2020/Accepted: 7 December 2020/Published online: 7 January 2021

(C) The Author(s) 2021

\begin{abstract}
Building on a summary of how turbulence influences biological systems, we reviewed key phytoplankton-turbulence laboratory experiments (after Peters and Redondo in Scientia Marina: Lectures on plankton and turbulence, International Centre for Coastal Resources, Barcelona, 1997) and Peters and Marrasé (Marine Ecology Progress Series 205:291-306, 2000) to provide a current overview of artificial turbulence generation methods and quantification techniques. This review found that most phytoplankton studies using artificial turbulence feature some form of quantification of turbulence; it is recommended to use turbulent dissipation rates $(\varepsilon)$ for consistency with physical oceanographic and
\end{abstract}

Handling editor: Luigi Naselli-Flores

Supplementary Information The online version of this article (https://doi.org/10.1007/s10750-020-04487-5) contains supplementary material, which is available to authorised users.

R. N. Arnott · L. D. Bryant · D. J. Wain $(\bowtie)$

Department of Architecture and Civil Engineering,

University of Bath, Bath, UK

e-mail: danielle.wain@7lakesalliance.org

M. Cherif

Department of Ecology and Environmental Sciences,

Umea University, Umeå, Sweden

Present Address:

D. J. Wain

7 Lakes Alliance, Belgrade Lakes, ME, USA limnological observations. Grid-generated turbulence is the dominant method used to generate artificial turbulence with most experiments providing quantified $\varepsilon$ values. Couette cylinders are also commonly used due to the ease of quantification, albeit as shear rates not $\varepsilon$. Dinoflagellates were the primary phytoplanktonic group studied due to their propensity for forming harmful algal blooms (HAB) as well as their apparent sensitivity to turbulence. This study found that a majority of experimental setups are made from acrylate plastics that could emit toxins as these materials degrade under UV light. Furthermore, most cosm systems studied were not sufficiently large to accommodate the full range of turbulent length scales, omitting larger vertical overturns. Recognising that phytoplankton-turbulence interactions are extremely complex, the continued promotion of more interdisciplinary studies is recommended.

Keywords Phytoplankton · Interactions $\cdot$ Harmful algal blooms $\cdot$ Dinoflagellates

\section{Introduction}

Turbulence is a key physical characteristic of aquatic systems that has profound impacts on phytoplankton population dynamics. Many early studies of these complex biological-turbulence interactions (Fig. 1) 


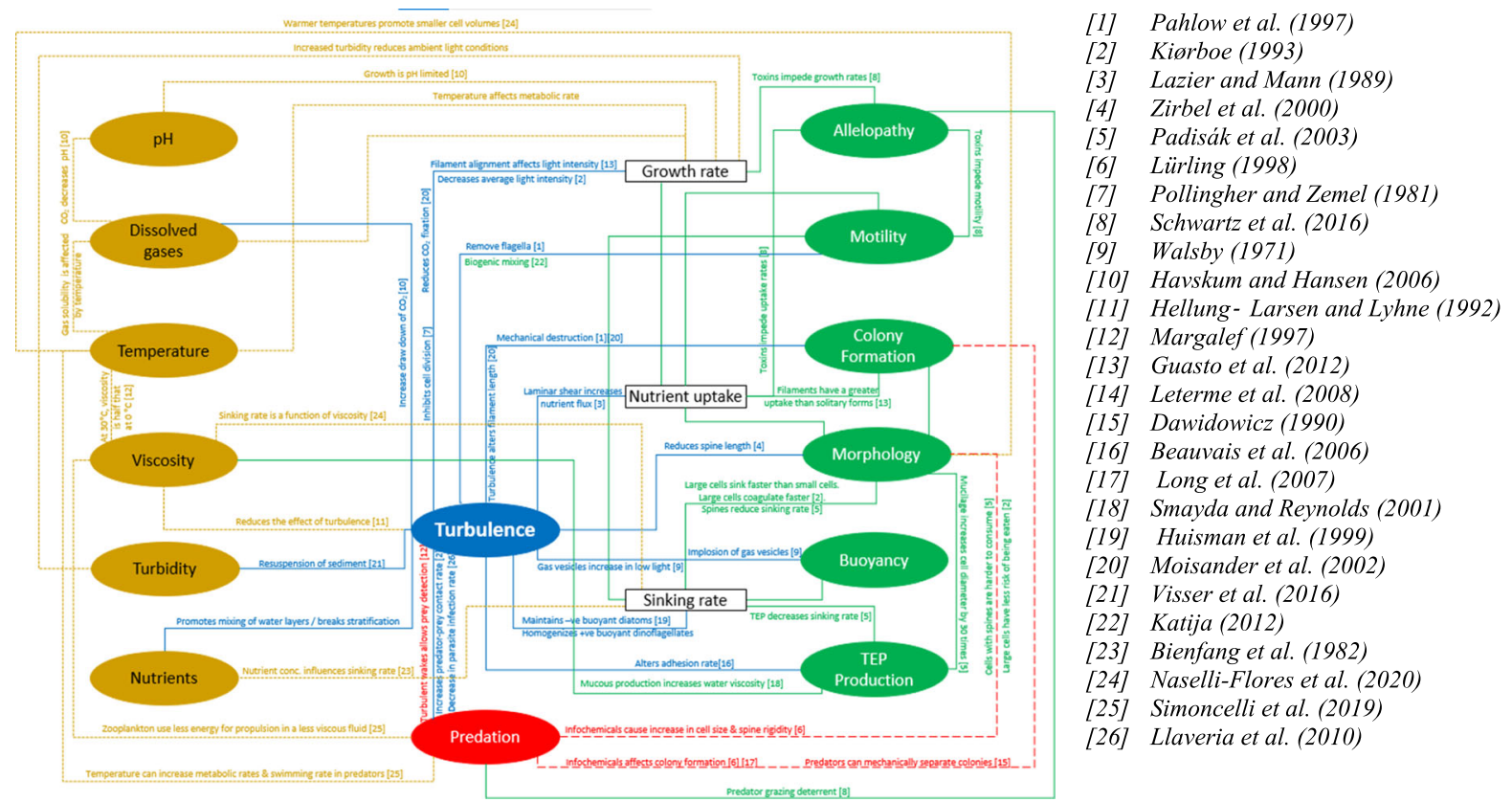

Fig. 1 Flow diagram summarising various links and feedbacks of phytoplankton-turbulence interactions. Green = biological characteristics; white $=$ rates; blue $=$ turbulence processes; red $=$ predation; gold $=$ water properties. Associated coloured

focussed upon the role of turbulence in homogenously redistributing phytoplankton species throughout the water column. Stably stratified water columns typically promote positively buoyant species, allowing them to access increased light levels and, in nearshore waters, nutrients trapped above the pycnocline associated with catchment runoff. This scenario is vastly generalised and broadly characterised; additional studies into the various biological-turbulence interactions have yielded a variety of complex feedback mechanisms (Fig. 1).

To understand this array of interconnected feedback mechanisms and accurately predict how phytoplankton behave in a given environment, researchers frequently adopt one of two approaches. The first is to model a general phytoplankton population using either a single, idealised species (Ross and Sharples, 2007; Ross and Sharples, 2008) or a combination of idealised species, e.g. positively buoyant dinoflagellates against negatively buoyant diatoms (Huisman et al., 1999). The second approach is to artificially produce turbulence in a mesocosm facility (hereafter referred to as a cosm to include facilities across an array of sizes) and expose either a monoculture, a mixture of species, or a text denotes the forcing factor for that link. Where appropriate, links are qualified with numbered references. Dashed lines are included to assist colour-blind readers in distinguishing problematic colours

natural population to varying levels of turbulence (Peters and Redondo, 1997). It is the latter that this review focuses upon.

This review begins with an overview of biologicalturbulence interactions, drawing upon key studies to highlight the complex relationship between phytoplankton and turbulence. Best practice is then discussed with regards to the experimental design of phytoplankton cosm studies. Building upon this, the main methods of artificial turbulence generation (grids, shaker tables, aeration and Couette cylinders are discussed and reviewed, with less-commonly used methods included in Appendix 1-Supplementary Material. This review culminates with a discussion of the different techniques used to quantify turbulence in cosm experiments, with lesser-used techniques found in Appendix 2-Supplementary Material.

Note that this review is limited to studies involving phytoplankton in controlled laboratory settings and, to this end, omits observations of natural systems as well as biological-turbulence interaction studies on higher trophic organisms (e.g. zooplankton and fish larvae). A total of 102 publications were used to complete this review. For publications where more than one 
generation technique was used, these have been counted as separate (a total of 8). For single experiments that yielded multiple publications (a total of 14), these have been counted as a single study. A summary table of all publications used for this review can be found in Appendix 3-Supplementary Material.

\section{Quantifying turbulence in aquatic environments}

Most aquatic environments are turbulent flows comprised of eddies of varying size. As a fluid is perturbed at the macroscale (e.g. by wind), the energy imparted to that fluid cascades down from larger to increasingly smaller eddies until is it dissipated by the viscosity of the water. When measuring turbulence, there are a number of different variables that can be used to quantify the turbulent field. If we consider the rate at which the kinetic energy dissipates due to viscous forcing (i.e. the rate of turbulence kinetic energy dissipation; $\varepsilon$ ), it is possible to quantify turbulence.

It is also possible to quantify turbulence via velocity shear. As a fluid flows past a surface, shear is generated as friction between the fluid and the surface causes a boundary layer. This layer diffuses away from the surface, perpendicular to the direction of the flow. At certain thresholds, the boundary layer can give way to vortex shedding as the flow switches from laminar to turbulent. Within the remit of this review, shear is only used to quantify turbulence in studies that make use of Couette cylinders where shear flow is used to generate turbulence inside the cylinder. For laboratory measurements to be comparable with those in the field, it is thus recommended that turbulence values are reported as $\varepsilon$ in units of $\mathrm{m}^{2} / \mathrm{s}^{3}$, which are the more commonly reported field units across disciplines.

\section{Study aim}

This review builds upon the seminal work of Peters and Redondo (1997) and incorporates literature from over the subsequent 20-plus years in order to ascertain best practice when it comes to laboratory-based turbulence generation studies. There is clearly the need for greater standardisation across turbulence studies to facilitate easier and more direct comparisons between studies. Peters and Redondo (1997) originally set out to "spark more interdisciplinary science," aiming to support biologists by introducing them to the world of turbulence.

As well as discussing the various methods of generating turbulence (along with accompanied mathematical principles), Peters and Redondo (1997) made a key discovery: $\varepsilon$ generated in laboratory experiments can commonly be up to orders of magnitude higher than the average level of $\varepsilon$ typically observed in the oceanic surface-mixed layer $\left(\varepsilon=10^{-5} \mathrm{~m}^{2} / \mathrm{s}^{3}\right)$. Many of the "classic" papers on the effects of turbulence on phytoplankton growth (White, 1976; Pollingher and Zemel, 1981; Savidge, 1981) actually made no attempt to quantify the levels of turbulence to which their phytoplankton populations were exposed. Thankfully, as this study area developed over time, practitioners retrospectively quantified their experiments; it is now standard to include estimates of $\varepsilon$ and/or other turbulence quantities (Table 1).

From descriptions of laboratory setups, Peters and Marrasé (2000) estimated that the level of $\varepsilon$ in some experiments could have been as high as $0.23 \mathrm{~m}^{2} / \mathrm{s}^{3}$. Results from experiments with exaggerated levels of turbulence may have water-quality applications such as artificial mixing in reservoirs and bathing water (Kirke, 2001; Visser et al., 2016). However, if the purpose of the experiment is to accurately model a biological-physical system that would occur in a natural aquatic system, then it is crucial for the experimental setup to be as representative as possible of the real-world. It is highly prudent to correctly quantify the level of turbulence generated prior to commencing a study to ensure that experimental conditions are representative of the environment being replicated.

\section{Biological-turbulence interactions}

Turbulence can have a profound influence on individual cells, specific species, and community composition in many ways. Most simply, high levels of turbulence can cause mechanical destruction by detaching flagella (Pollingher and Zemel, 1981), directly impacting motility. Turbulence also acts as a mechanism by which to homogenously distribute positively buoyant, motile species throughout a water column or to resuspend negatively buoyant, nonmotile species; this directly impacts cell access to the 
Table 1 Comparison of the main turbulence generation techniques taken from publications between 1953 and 2020 inclusive $(n=102)$

\begin{tabular}{lllll}
\hline Turbulence generation method & Quantified & Quantified elsewhere & Unquantified & Total Studies \\
\hline Aeration & 1 & 3 & 7 & 11 \\
Couette & 15 & 3 & 0 & 18 \\
Grid & 29 & 2 & 1 & 32 \\
Shaker & 6 & 9 & 4 & 19 \\
Other & 14 & 1 & 6 & 21 \\
\hline
\end{tabular}

As well as the number of publications associated with each technique, we also see the proportion of studies which include turbulence quantification. See also Fig. 6 for a chronology of publications for different turbulence generation methods

photic layer and/or the light climate to which a cell is exposed (Kiørboe, 1993; Visser et al., 2016). Thus, the turbulent regime of a water body can have a profound impact on the phytoplankton community composition with corresponding effects further along the food web. To this end, turbulence has been seen to increase both predator-prey encounter rates (Rothschild and Osborn, 1988) and contact rates between parasites and phytoplankton cell hosts (Llaveria et al., 2010).

At the cell level, turbulence can impact cell growth via altering rates of nutrient uptake and exposure to light. Phytoplankton cells uptake nutrients from the surrounding water via diffusion; reduced flow at the cell surface causes the water surrounding the cell (i.e. the concentration boundary layer) to become nutrient depleted (Prairie et al., 2012) and replete with waste (Lazier and Mann, 1989; Kiørboe, 1993). Turbulent flows are seen to increase the laminar shear across the cell surface, eroding the concentration boundary layer and causing a corresponding increase in nutrient flux to the cell (Lazier and Mann, 1989; Kiørboe, 1993; Arin et al., 2002; Peters et al., 2006). Conversely, turbulence can also reduce the rate of cell division (Sullivan et al., 2003) with prolonged exposure to high turbulence intensities resulting in increased cell mortality (White, 1976; Pollingher and Zemel, 1981). Even short duration, high-intensity turbulence applied at a specific time in the cell cycle can inhibit cell division (Pollingher and Zemel, 1981). Turbulence can also induce the "flashing light effect" (a.k.a., the light-dark cycle, intermittent illumination, light intensity fluctuation and/or dynamic light condition; (Sato et al., 2010)) in cells. This phenomenon has been observed to increase the photosynthetic efficiency in cultured species exposed to intermittent light fluctuations (Laws et al., 1983; Grobbelaar, 1989) via a reduction in photoinhibition (Nedbal et al., 1996) thought to be linked to the light fluctuations that a cell would be exposed to within a turbulent environment.

Turbulence also can cause changes in cell morphology. For example, the dinoflagellate Ceratocorys horrida Stein experienced a reduction in cell size and spine length in response to high turbulent intensities, an adaptation postulated to allow cells to sink below the more turbulent conditions and reduce risk of mechanical damage (Zirbel et al., 2000). Cell morphology is also linked to light climate with elongated particles becoming aligned in the direction of flow, thereby increasing the backscatter of light in the water column (Guasto et al., 2012). Morphology is also linked to nutrient uptake, the rate of which preferentially increasing in larger cells when compared to smaller cells in turbulent conditions (Guasto et al., 2012).

Further studies linking turbulence to morphology and surface-area-to-volume (SAV) ratios across different species suggested these parameters to be crucial in determining nutrient uptake (Fraisse et al., 2015). Growth rate of large species was often exceeded by that of smaller species in nutrient-limited conditions (Cózar and Echevarría, 2005), whereas shape dictated how a species behaved hydrodynamically while in turbulent flows and while sinking (Padisák et al., 2003). Clearly, shape and SAV ratios are interlinked; elongated cells were seen to outcompete spherical cells with regards to nutrient acquisition (Pahlow et al., 1997).

Morphology also plays a key role in how colonial, chain-forming filamentous species interact with turbulent fields; for example, longer filaments sink faster 
in calm conditions, but under turbulent conditions a filament can grow to greater sizes as a result of turbulence-induced increases in light access (Fraisse et al., 2015). Chain-forming, postulated to be a means for avoiding grazing (Kiørboe, 1993), also provides a mechanism by which to increase form drag and thereby reduce sedimentation (Padisák et al., 2003). Turbulence has been observed to separate large colonies, thereby separating filament chains into smaller sections (Pahlow et al., 1997) which are able to sink and access additional nutrients at depth (Padisák et al., 2003). The ability of a colony to deform in different flow environments is thought to give colonial species a competitive advantage in a wider range of turbulent regimes (Guasto et al., 2012). Turbulence-enhanced nutrient uptake is also seen to preferentially affect colonies when compared to singular cells (Guasto et al., 2012). Chain-forming species exhibit a range of lengths, orientations and flexibilities, all of which affect their hydrodynamic properties. Compared to flexible chains, increasingly stiffer chains not only exhibit higher rates of nutrient consumption but also experience larger nutrient fluxes (Musielak et al., 2009). With focus on phytoplankton as a carbon pump, colonial diatoms are known to be prolific fixers of carbon dioxide $\left(\mathrm{CO}_{2}\right)$ where under turbulent conditions, they export carbon from the upper ocean to depths by forming fast-sinking aggregates. To this end, rates of turbulence-enhanced carbon uptake have been observed to be higher in chain-forming species than in individual cells (Bergkvist et al., 2018).

The traditional view of phytoplankton behaving as benign passengers at the whims of forces within the water column holds for macroscale flows; however, the various experiments described within this review act to showcase a dynamic group of organisms capable of complex abilities and feedback mechanisms permitting them to gain a foothold over competing species by altering their properties to suit the conditions of the water column. Increasingly, researchers are recognising that different phytoplankton have an array of ecological adaptations that allow them to prosper within an array of various turbulent environments (Margalef, 1997; Fraisse et al., 2015). With emphasis placed on the effect of turbulence, Fig. 1 allows us to appreciate the complexity of turbulenceplankton interactions. Further weight is added herein to recommendations found in key papers (Margalef,
1997; Peters and Redondo, 1997) which characterise turbulence within a water column to be as significant a biological determinant as temperature or salinity, thereby emphasising the importance of measuring shifts in phytoplankton communities and turbulence concurrently.

\section{Experimental design}

\section{Facility considerations}

Before evaluating different methods of turbulence generation, the experimental vessel(s) itself should be considered as something as simple as the shape, scale and material can considerably influence the experiment if not properly accounted for. As such, the following section discusses the potential implications of tank volume, tank shape, the material the tank is constructed from and how the tank is filled.

\section{Volume of tank}

Crossland and La Point (1992) posed the question: "How big does a mesocosm have to be to provide a realistic simulation of the natural environment?" The answer is very dependent on the scale and scope of study taking place. Throughout the literature, however, the terms nanocosm, microcosm and mesocosm are frequently used interchangeably. Whether a cosm is classed as nano-, micro-, or meso- is open to interpretation with some using volume as the distinguishing feature (Waller and Allen, 2008; Alexander et al., 2016), while others use diameter or length (Kangas and Adey, 2008). In summary, Solomon and Hanson (2014) provided the best characterisation of the different cosms (Table 2). Traditionally, researchers used small $(<1$ L) nanocosms described as "simplified, physical models of an ecosystem that enable controlled experiments to be conducted in the laboratory or in situ" (Matheson, 2008). Increasing in size leads sequentially to microcosm and mesocosm systems, generally described to be "bounded and partially enclosed outdoor experimental setups falling between laboratory microcosms and the large, complex real-world macrocosms" (Odum, 1984). These facilities may be housed inside or outdoors (i.e. on land or in water) depending on the nature of the setup. For outside enclosures suspended within an aquatic 
Table 2 Characterisation of different cosms (2014)

\begin{tabular}{lllc}
\hline & Nanocosm & Microcosm & Mesocosm \\
\hline Volume (L) & $1-100$ & $100-15000$ & $>15,000$ \\
No. of trophic levels & 2 & $3+$ & $3+$ \\
Optimum study duration & $<8$ weeks & $<1$ season & $>1$ season \\
Typical location & Inside & Inside or outside & Outside \\
\hline
\end{tabular}

environment, Solomon and Hanson (2014) suggested the term 'limnocorral' to differentiate these from facilities on land, while Parsons et al. (1978) opted for a controlled ecosystem enclosure.

With regards to biological studies, a larger experimental volume supports greater biodiversity and allows for a larger number of trophic levels to be observed concurrently (Alexander et al., 2016); conversely, smaller microcosms typically exclude higher trophic levels due to size constraints (Matheson, 2008). With regards to turbulence, vertical overturns are known to exist between $10^{-3}$ and $10^{1} \mathrm{~m}$; while smaller cosms represent the smaller end of this range, clearly a much larger tank would be required in order to capture the upper range. After all, it is not possible to produce a $10 \mathrm{~m}$ vertical overturn if the tank itself is shallower than $10 \mathrm{~m}$ depth. Using cosm volume as an indicator of maximum turbulent overturn size within a particular experiment, a majority of studies were found to use fluid volumes smaller than $1 \mathrm{~m}^{3}$ (Fig. 2). As expected, it is larger volume limnocorral studies that make up a bulk of the experiments above this $1 \mathrm{~m}^{3}$ threshold.

\section{Shape of tank}

Peters and Redondo (1997) put forth the assumption that biologists tend to use cylindrical tanks as, in theory, these display a higher degree of homogeneity. Conversely, physical studies are generally undertaken in cuboid tanks as the corners disrupt secondary flow effects; at the same time, modelling flow within square-based tanks is considered simpler mathematically. However, cuboid tanks are considered less homogenous overall due to the presence of corners (Peters and Redondo, 1997) which can cause (1) material to collect, (2) organisms to grow there and/or (3) changes in the turbulent field. In a comparison between turbulence generated in smooth- and baffledbottom flasks, $\varepsilon$ values were seen to be two orders of magnitude higher in the latter (Kaku et al., 2006). The shape of a tank can clearly play a significant role in the turbulence regime within.

Matheson (2008) acknowledged the importance of SAV ratio in microcosm design; those with a large SAV ratio can promote edge communities of biofilms or cause other organisms to congregate to avoid predation. As such, these biological "wall effects" can add significant bias into an experiment; efforts should hence be made to use facilities with small SAV ratios. The size and aspect ratios of the test vessel would be expected to affect the growth rate for many reasons. High-volume growth "ponds" (i.e. vessels with a shallow depth but increased exposed water surface area) are designed to maintain as much of the population in the photic layer as possible while also reducing the effects of shadowing. A larger exposed water surface area would not only increase gas exchange across the boundary but would also promote a higher evaporation rate.

\section{Material of tank}

Vessels may be constructed out of an array of different materials depending on availability and size requirements. Firstly, it is essential that the material of the tank does not influence the fluid medium inside the tank. As such, it is not advised to use ferrous materials to construct mesocosms as not only does this add iron to the fluid medium (which is a photosynthesislimiting micronutrient; (Martin and Michael Gordon, 1988) but the tank itself is also at risk of corrosion, especially if using saline fluid media.

Other materials may also cause micronutrients to be leached into the culture medium; glass has the potential to provide a source of silicon, known to be a limiting nutrient for diatoms (Kilham, 1971). Hellung-Larsen and Lyhne (1992) studied the effects of vessel material on the rates of cell division in the protozoan Tetrahymena sp. and observed no significant difference when using glass, siliconized glass and plastic. 


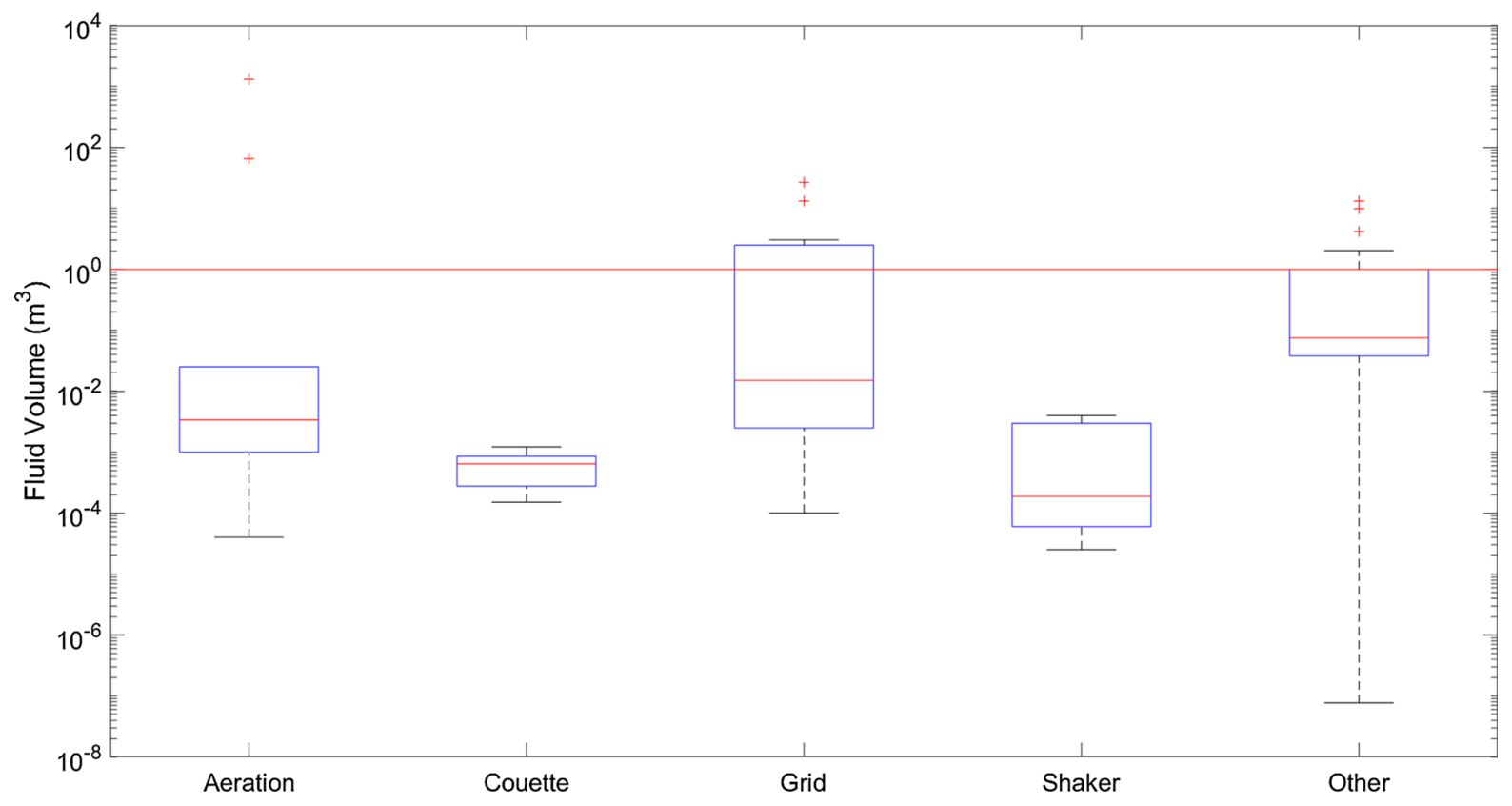

Fig. 2 Boxplots of approximate fluid volumes involved with different types of turbulence generation experiments. Central line in each box is the median; top and bottom of each box indicate the 25th and 75th percentiles. Whiskers extend to the most extreme data points not considered outliers, with outliers

With an increasing propensity for ecologists and other researchers to experiment with three-dimensional (3D) printing technology, it has been observed that certain extrusion materials, particularly resins, remain toxic to aquatic organisms for some time. Should a microcosm tank be 3D-printed in resin; however, exposure to ultraviolet (UV) light can reduce its toxicity substantially (Behm et al., 2018).

Conversely, many cosms are constructed from artificial polymers such as acrylate, polyvinyl-chloride (PVC) and polycarbonate which all undergo photodegradation reactions under UV light (Yousif and Haddad, 2013), potentially releasing toxins that could adversely influence productivity. In a similar vein, the presence of polystyrene nanoplastics were seen to reduce the chlorophyll content of the diatom Chaetoceros neogracilis VanLandingham with subsequent implications on cellular growth and photosynthetic efficiency (Gonzalez-Fernandez et al., 2019). As such, it is crucial that the tank material itself is not influencing the growth rate of the organisms being studied. Some plastics are also permeable to certain gases; depending on the nature of the study, this should plotted as plus-signs. Continuous horizontal line indicates a volume of $1 \mathrm{~m}^{3}$, considered to be the minimum volume required to capture realistic turbulence length scales Note the log scale on the y-axis

also be considered and may even be desirable (Matheson, 2008).

As well as releasing chemicals into tank water, certain cosm materials can absorb chemical species from the water (Kangas and Adey, 2008). Zhou et al. (2016) submerged Plexiglass tanks in water for 15 days prior to their experiment to allow the tanks to absorb and/or release any chemicals and equilibrate accordingly. Of the cosms studied, a third was comprised of plastics that undergo UV degradation (Fig. 3). Another third was made of glass which may be correlated to the high proportion of studies using glass Couette cylinders and Pyrex vessels on shaker tables.

Typically, biologists cultivate cells in transparent vessels to maximise incident light that allows cells to reproduce further. This eliminates any light-gradient within the tank that would be present in nature. As such, it is advised to use opaque materials when studying the effects of turbulence; this generates a light-gradient through the tank which can have a significant impact on results, especially when using phototactic or motile species or those with the ability to regulate their buoyancy. It should also be noted that 


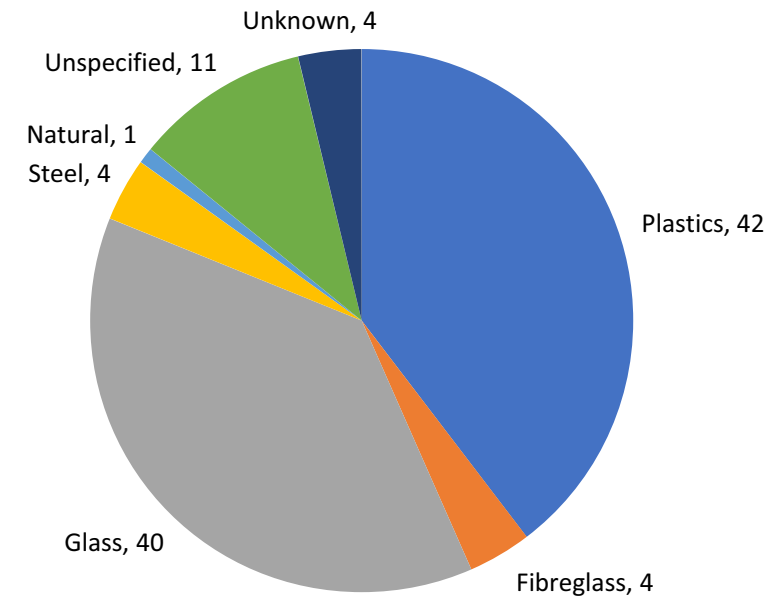

Fig. 3 Materials used in cosm design (based on $c=102$ studies). Plastics refer to tanks comprised of acylate, polycarbonate, polyethylene and polyvinyl-chloride, all of which are known to undergo UV degradation. Glass refers to both standard glass and Pyrex. For cosms comprised of more than one material $(n=2)$, these materials have been counted separately

while surface shading is a natural phenomenon that regulates phytoplankton growth, light introduced through transparent walls is susceptible to biofilm growth resulting in decreased light levels over time (Matheson, 2008). Some practitioners have avoided this effect via a periodic scrubbing of the tank walls with a brush or similar (Zhou et al., 2016).

\section{Filling}

Phytoplankton-turbulence studies that use smaller nano- and microcosms typically study the effects of one or two different species at a time based on seeding of the cosms with laboratory-cultivated cells grown in incubators. However, larger mesocosms and limnocorrals are typically used to look at natural planktonic communities that may be comprised of multiple trophic levels and organisms of different sizes. Land-based facilities are typically filled via pumping offshore waters from a particular depth into the enclosures (Båmstedt and Larsson, 2018). Ideally, sets of cosms will be filled simultaneously or as close timed as possible to insure homogeneity across all replicate cosms. It is important that the pump filling system does not inadvertently preclude any larger species nor damage them in their transport through the pump system (Striebel et al., 2013). Some facilities are able to filter certain size fractions from the inflow water (Båmstedt and Larsson, 2018), thereby allowing, e.g. microzooplankton through but omitting mesozooplankton that might graze upon certain size fractions or cause morphological changes via infochemicals (Long et al., 2007; Fig. 1).

Environmental variables

Having evaluated potential issues that may arise within different facilities, we next considered how environmental variables within the cosms may be influenced by particular experimental setups. Specifically, we looked at the implications of study duration, nature of the turbulence generated, light climate within the tank and general properties of the water itself.

\section{Duration of study}

As suggested by Table 2, the duration of a study is somewhat dictated by the volume of the tank, with larger facilities being able to accommodate a higher number of trophic levels (Solomon and Hanson, 2014). It stands to reason that any change in the turbulent regime within the tank will take time for its effects to cascade through a wider array of trophic communities. Depending on the rate of cell division across different species (and given conditions that promote or inhibit growth), it is expected that a phytoplanktonic community would adjust to a new turbulent regime within a few days. Given a minimum cell division rate of $\sim 0.5$ divisions per day (Banse, 1991), two days should account for cells to replicate at least once.

It is important to account for the effects of turbulence on growth due to changes in light regime (Kiørboe, 1993), changes in cell division rate (Pollingher and Zemel, 1981) and morphological changes to future generations (Zirbel et al., 2000). Once the new turbulent regime is established and the community adjusts accordingly to the new physical environment, ecological processes will dominate in regard to inter-species and trophic interactions.

\section{Intensity or level of turbulence}

If the purpose of conducting laboratory experiments is to ascertain the effect(s) of turbulence on a planktonic population, then it is crucial for the generated 
turbulence to properly represent the real-world, naturally turbulent environment to which organisms would be exposed. Using large, external limnocorrals may seem to be the easiest way to ensure that the turbulence within a cosm is as natural as possible; however, it has been observed that enclosing a portion of a water body within a cosm can significantly reduce the internal mixing regime when compared to conditions immediately outside the enclosure (Striebel et al., 2013).

As well as the tendency to produce excessive and unrealistic levels of turbulence within a cosm (Peters and Marrasé, 2000), there are a number of reasons to rethink existing approaches to artificially generated turbulence. It is important to consider how turbulence manifests itself within aquatic environments where turbulence is generally relatively weak. Observations suggest that $\varepsilon$ typically exists between $10^{-10}$ and $10^{-7}$ $\mathrm{m}^{2} / \mathrm{s}^{3}$, both in central ocean systems (Fuchs and Gerbi, 2016) and freshwater lakes (Wüest and Lorke, 2003). While wind-mixed and convectively mixed surface layers seldom exceed $10^{-5} \mathrm{~m}^{2} / \mathrm{s}^{3}$ in the open ocean, surf zone $\varepsilon$ values of up to $10^{-2} \mathrm{~m}^{2} / \mathrm{s}^{3}$ have been observed (Fuchs and Gerbi, 2016). Of the experiments reviewed here, a majority focussed on the upper range of $\varepsilon$ found in natural environments (Fig. 4).

In addition to being relatively weak, turbulence in natural environments can be highly sporadic, both temporally and spatially (Waterhouse et al., 2014). Thus, laboratory experiments that constantly force turbulence generation and aim for isotropic conditions across relatively small tank volumes are unrepresentative of natural conditions. In particular, direct and indirect turbulence avoidance strategies have been observed in planktonic organisms at a number of trophic levels (Franks, 2001; Pringle, 2007). Thus, for a cosm to properly represent the natural environment, a refuge region of less-turbulent water should be incorporated into the experimental design to allow the organisms some respite from intense turbulence and to facilitate natural behaviour (Franks, 2001). It is thus recommended that experimental designs of cosms need to be large enough to include this refuge region. While this is thought to be particularly applicable to zooplankton studies, many motile phytoplankton species position themselves within the water column to obtain light and/or nutrients and would also benefit from tank refuge regions.

\section{Light}

Many standard biological growth facilities are designed to maximise growth with regards to the light climate of the vessel. As mentioned previously, it is crucial for incident light within turbulence generation tanks to attenuate with depth. The biological-turbulence interactions that underpin the critical depth hypothesis (Sverdrup, 1953) would be invalidated if light levels did not attenuate with depth.

With regards to the light spectrum that organisms are exposed to, it is best to use direct sunlight to capture all spectrographic components of the sun at surface level. While this will be the natural default in outdoor facilities and limnocorrals, indoor facilities traditionally have relied on filament lamps that had a tendency to over-represent light within the infrared parts of the spectrum, causing heating to the cosm surface and various thermal lid effects (Båmstedt and Larsson, 2018). Conversely, filament lamps underrepresent the UV component of sunlight and, while UV light is attenuated quickly in the water column, it can still have an influence on cosm ecology. For example, waters with high levels of coloured dissolved organic matter (CDOM) have been shown to increase the attenuation of visible light, thereby reducing the depth of the upper photic layer (Reynolds, 2009). CDOM preferentially absorbs visible light towards the blue end of the spectrum as well as UV. The UV light interacts with an array of complex compounds found in CDOM, causing them to decompose into smaller compounds which can more easily interact with other biochemical processes. Thus, the presence of CDOM in the water column can have a profound impact on primary productivity with depth (Coble, 2007). Paczkowska et al. (2017) showed the explicit link between CDOM and the phytoplanktonic community; as CDOM degrades in the environment, it provides an important nutrient supply for heterotrophic bacteria which are a potential food source for any mixotrophic species. Furthermore, under the restricted light conditions associated with CDOM, phytoplankton respond by increasing the cellular concentration of the photosynthetic pigments, including chlorophyll- $a$. These restricted light conditions can also promote a shift towards species with smaller cell sizes (Paczkowska et al., 2017).

With the advent of halogen and LED lights, it is now easier to reproduce the surface sunlight spectrum 

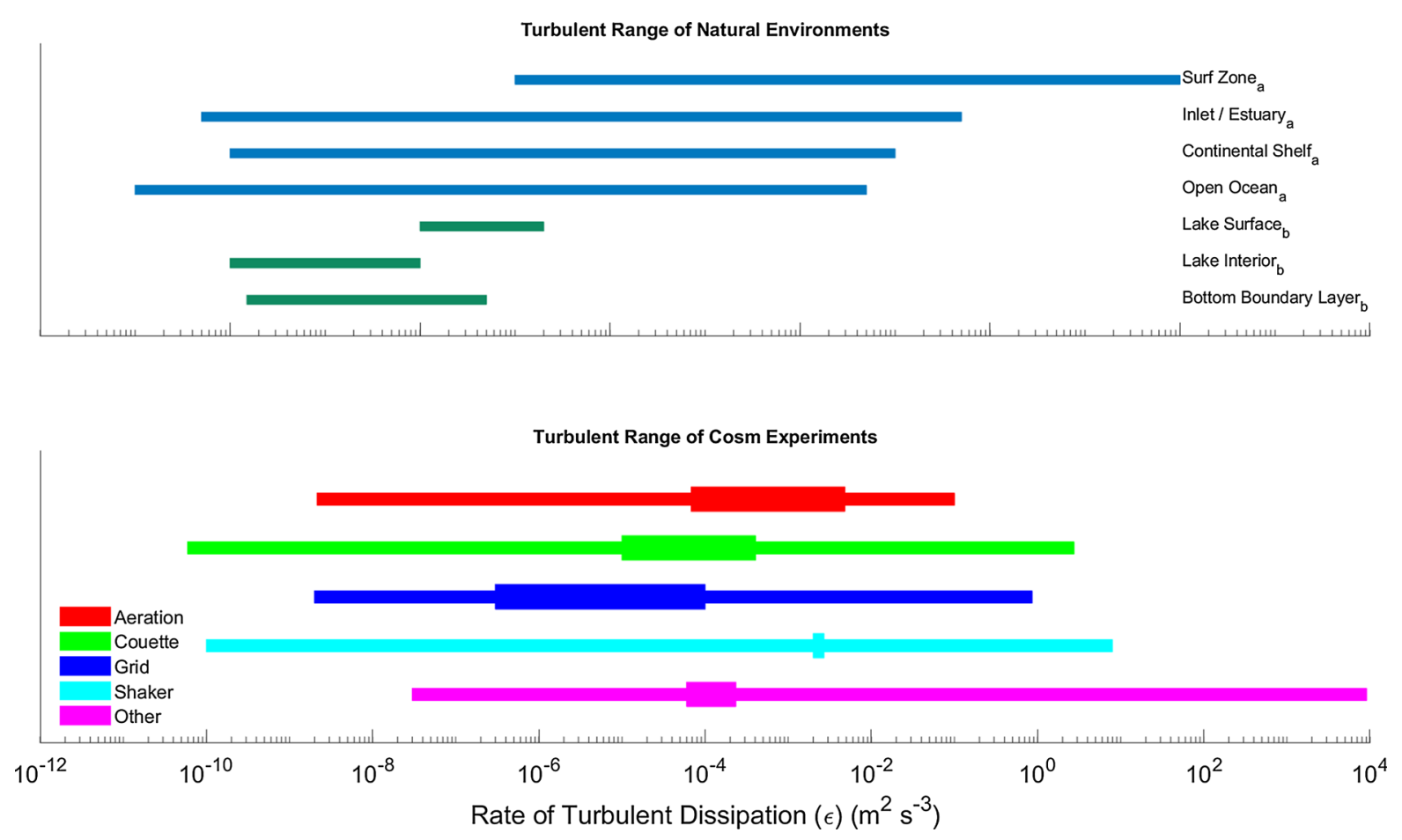

Fig. 4 Upper: comparison of range of turbulent dissipation rates $(\varepsilon)$ found in marine and lacustrine environments taken from Fuchs and Gerbi (2016)(a) and Wüest and Lorke (2003)(b) respectively. Lower: $\varepsilon$ produced from turbulence generation

within indoor cosms, accounting for UV, visible and infrared components accordingly. Care should still be taken to measure the photoactive radiation (PAR) within the cosm to ensure it is attenuating sufficiently with depth and is not too bright to cause photoinhibition of cells. As for the duration of light exposure, it is recommended that the day-night cycle match that of the natural levels the organisms would experience. While a simple binary on-off timer may be used to achieve this, it is better to include faders in the cosm facility design to gradually increase or decrease light levels over the course of the day as they would occur in nature.

Additionally, the potential for the turbulence generation apparatus in a cosm to shade the water below should be considered. Placing grids, paddles, impellors and similar structures into a tank can decrease the amount of surficial light that reaches the bottom of cosm. This was considered to be an issue in a study by Rijkeboer et al. (1990), who promptly replaced a steel paddle with a transparent Perspex one to minimise this effect. studies evaluated for this review $(n=102)$. Horizontal lines span total ranges (thin lines) with the lower and upper logmedian $\varepsilon$ limits (thick lines) for each generation method

\section{Temperature and salinity}

As with light levels, it is also prudent to expose test organisms to temperatures and salinities that they would ordinarily be subject to in natural aquatic environments. While temperature has the ability to directly alter photosynthetic and respiration rates in phytoplankton (Staehr and Sand-Jensen, 2006), there are also indirect temperature effects including variations in the solubility of gases. Both temperature and salinity have an influence on water viscosity which could affect microscale turbulence dynamics. In addition, temperature has been found to be inversely related to cell volume (Naselli-Flores et al., 2020), resulting in additional hydrodynamic variations that need to be considered.

\section{Biological considerations}

While smaller nano- and microcosm experiments lend themselves well to studying the effect of turbulence on a single species, larger mesocosms can be used to 
investigate interactions between two (or more) species (Havskum, 2003; Stoecker et al., 2006; Pannard et al., 2007; Fraisse et al., 2015; Martínez et al., 2017). Due to their apparent sensitivity to turbulence as well as their propensity to form harmful algal blooms, a majority of studies have understandably focussed on the dinoflagellate group (Fig. 5). Furthermore, this group includes species with bioluminescent abilities; the light intensity emitted can be used as a proxy for turbulent shear, thereby facilitating the quantification of shear in cosm experiments (Stokes et al., 2004).

If using a natural planktonic population, it is possible to omit microzooplankton by filtering the water used prior to filling the cosms (Båmstedt and Larsson, 2018). While this is not suitable for predatorprey interaction studies, the removal of grazing should allow the subtle impacts of turbulence interactions on the phytoplankton community to be more easily observed. Choosing the correct filter to omit zooplankton grazers but not affect the larger size fraction of phytoplankton can be difficult due to the overlap in sizes of these groups. It is also likely that a natural phytoplankton population might contain mixotrophic ciliates and dinoflagellates that graze on other species.

\section{Methods of turbulence generation}

There are many ways to artificially generate turbulence in a laboratory environment; reviews of each of these different techniques and notable case studies for each are provided in this section. An analysis of previous methods identified that most studies use just four different methods: bubbling aeration, Couette cylinders, oscillating grids and laboratory shaker tables.

The chronology of publications (Fig. 6) mirrors the information displayed in Table 1; clearly grid-generated turbulence is the "industry favourite" with regards to phytoplankton-turbulence studies. Despite a boom in studies between 2000 and 2010, the recent decade has seen a decline of bio-turbulence publications; the lowest since the pre-1970s.

\section{Oscillating grids}

A standard way to generate turbulence within a tank is to use a grid mesh which is placed in the tank and connected to a mechanism that allows that grid to move through the water. This technique, referred to as "a favourite in fluid dynamics experiments" (Guadayol et al., 2009b) is often the preferred method of turbulence generation due to its simplicity as well as its established use in an extensive number of studies of
Fig. 5 Proportion of different phytoplanktonic groups used in the evaluated turbulence interaction experimental studies. Number of publications featuring that group is included next to each segment. "Natural" refers to experiments that made use of indigenous populations

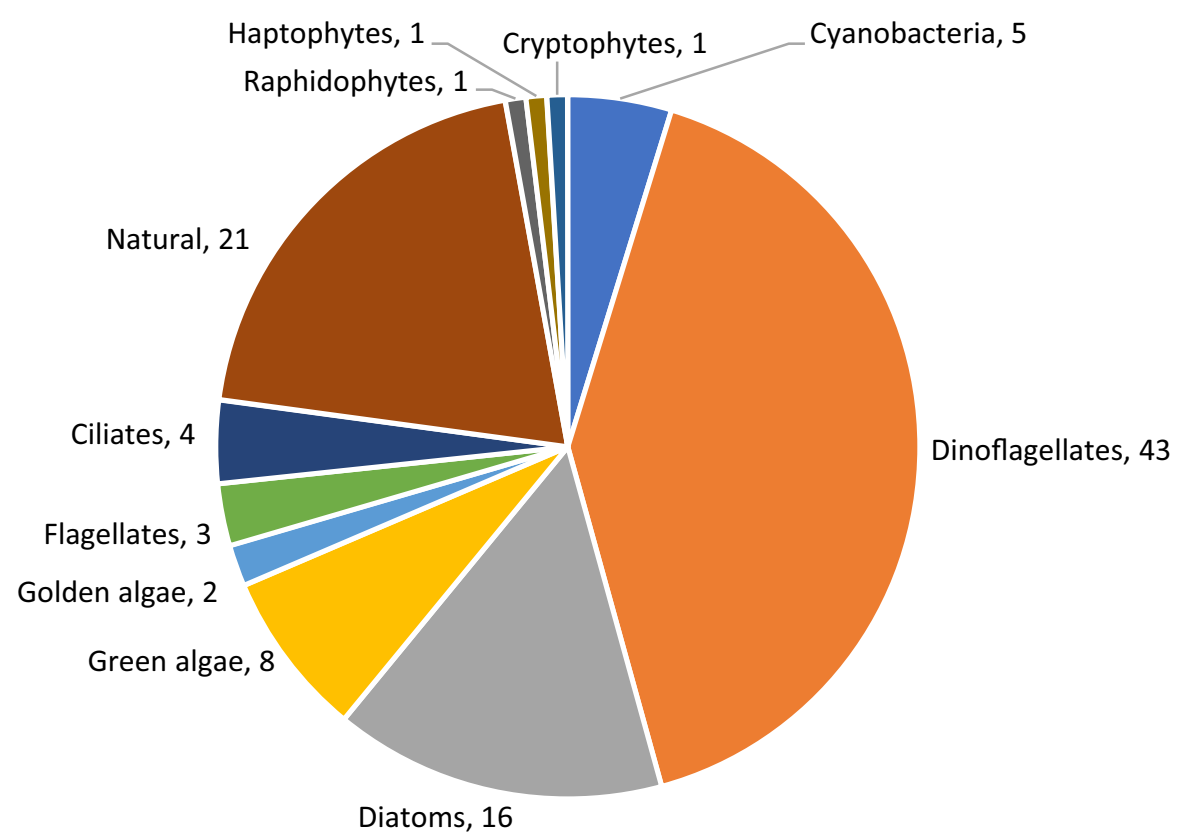




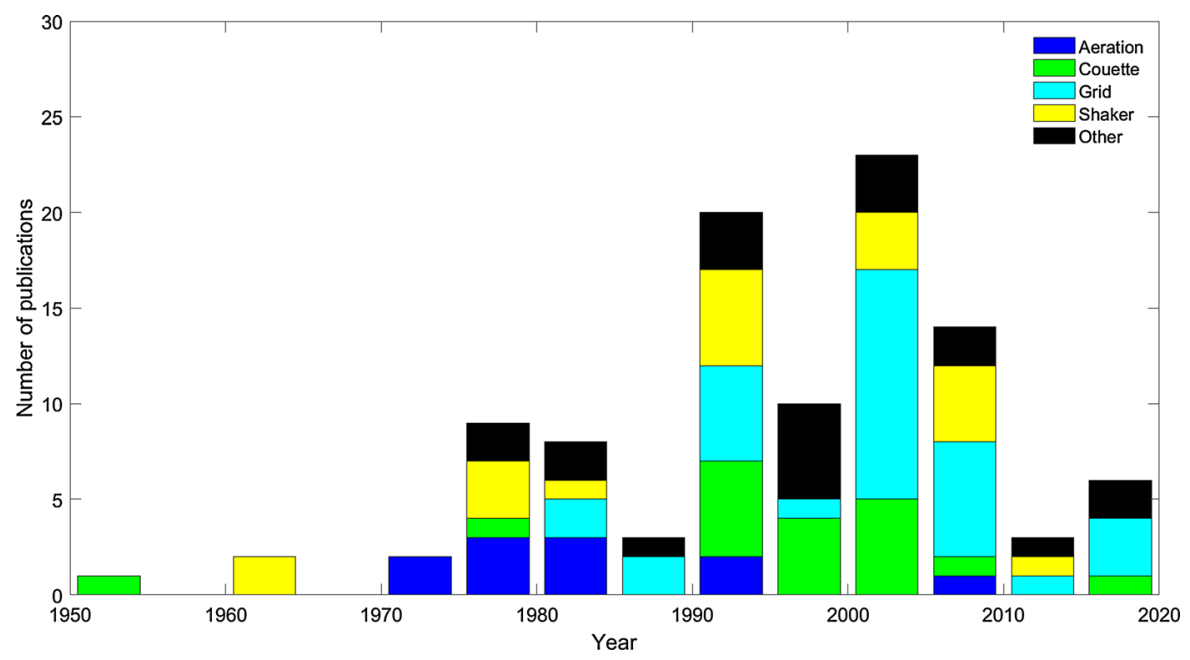

Fig. 6 Stacked bar chart of phytoplankton-turbulence publications by year showing the proportion of different turbulence generation techniques used

this nature. Grids are typically of a similar width/diameter to the test tank and are a simple way to ensure a consistent turbulent field across the width of a tank. Typically, the grids are attached to a motor that allows them to oscillate vertically or horizontally at a given frequency and stroke length. A majority of these studies quantify $\varepsilon$ (Table 1; Fig. 6), whereas early experiments simply used motor settings or revolutions per minute (rpm) as a proxy for turbulence intensity.

As with the tank material, the grid itself can be made from any material but it is important that the grid does not corrode or deteriorate with time and remains biologically inert. For this reason, the use of ferrous metals is discouraged as these materials will not only degrade in saline water but will also provide a source of iron micronutrients. Netlon meshes are typically used as they come in a variety of mesh sizes and are hardwearing, easily available, and corrosion-resistant. It is also possible to coat metal grids in inert substances such as nylon (Savidge, 1981).

In a thorough comparison between turbulence generated by grids to orbital shakers, Guadayol et al. (2009b) measured turbulence generated in a variety of different sized vessels ranging from small $0.8 \mathrm{~L}$ nanocosms up to $2500 \mathrm{~L}$ microcosms. As well as tank size, different grid configurations were trialled with variations in mesh size, bar width, grid diameter and cross-sectional shape. Study results show that the turbulence generated using grids was surprisingly isotropic (especially given the array of tanks size, grid dimensions and oscillation speeds) but with the caveat that grid stroke length had to be comparable to the depth of the tank. As such, Guadayol et al. (2009b) recommended using the maximum stroke length possible in order to ensure isotropy.

\section{Vertically oscillating grids}

In order to mimic surface layer mixing, grids are typically suspended from the top of the test tank. Grid nets can be singular (Savidge, 1981) or suspended in series of two or more grids (Estrada et al., 1987; Alcaraz et al., 1988; Berdalet, 1992). There is also the option of suspending an inclined, rotating ellipsoidal grid at a specific depth to promote mixing horizontally as well as vertically (Estrada et al., 1987). While investigating an alternative method to using grids, a number of disadvantages to using grid systems were identified by Webster et al. (2004). Having an object moving through the study tank interferes with many direct flow measurement techniques; however indirect techniques, such as particle tracking velocimetry, can be readily used. Moving grids can also increase the likelihood of mechanical damage to the study organism. In studies where the grid oscillates in only a small fraction of the cosm, the turbulence field produced is non-isotropic and directional in accordance with the direction of the grid motion. In this instance, the turbulence generated is also heterogeneous as it decays with increasing distance from the grid. Webster 
et al. (2004) also cited size, expense and complexity of apparatus as major disadvantages of grid systems; in reality, however, a simple oscillating grid is vastly simpler than many other turbulence generation methods described herein. Furthermore, Warnaars et al. (2006) recognised that steep turbulence gradients are typically recorded with grid systems; $\varepsilon$ is highest near the grid but decays rapidly with distance from the grid. In addition, ancillary flows are seen to accompany the primary flow field which exposes any test organisms to a wider range of turbulent regimes than may be desired. Overall, Peters and Redondo (1997) discouraged the use of oscillating grids on the grounds that the turbulence produced is not properly representative of naturally occurring turbulence.

One disadvantage of grid systems is the steep turbulence gradients found around the grid itself. If test organisms are permitted in and around the oscillating grid, they not only risk mechanical destruction but are also exposed to a wider range of $\varepsilon$ than they would in a natural environment. To prevent organisms from interacting with the region of grid oscillation, MacKenzie and Kiørboe (1995) used a fine mesh placed below the grid. The study focussed on swimming behaviour and encounter rates between copepod larvae and cod/herring larvae; thus, the barrier mesh size was selected to allow the prey copepods to interact with the grid region, while the fish larvae were unable to enter this region. The addition of the mesh screen is a notable improvement to studies of this nature but could interfere with the turbulent field produced by the oscillating grid. There is also the possibility that prey could pass through the mesh screen where it could then be subjected to advantageous conditions for increased growth. The presence of the screen could then prevent the now larger organism from passing back through the mesh. In the case of phytoplanktonic studies with incident light from above, this could provide an intrinsic bias to the study.

\section{Horizontally oscillating grids}

While most practitioners opt for vertically oscillating systems, there are times when a horizontal system is more suitable. To reduce the likelihood of resuspension of filamentous and dense species that sediment to the bottom, horizontal grids are better suited if using a mixed phytoplankton community as shown in a study by Fraisse et al. (2015). Six different phytoplankton species were selected to represent an array of morphologies (elongated shapes, flattened shapes and motile species), densities, growth rates and sizes. The study showed that the species selected that had high sinking rates were unable to outcompete those that could maintain their positions in the upper column. Similarly, Schapira et al. (2006) made use of horizontal grid systems taking care to produce both realistic and quantified turbulence measurements. Opting for low, medium and upper limits of turbulence found in the English Channel, the researchers investigated the impact of this on the colony-forming dinoflagellate Phaeocystis globosa Scherffel. Results show that turbulence enhanced colony growth and formation to a threshold amount after which turbulence was found to impede cell growth via a postulated reduction in cell division (Schapira et al., 2006).

\section{Vibrating grids}

In addition to oscillating grids, vibrating grids have also been used; to study the effects of turbulence on zooplankton behaviour, Saiz and Alcaraz (1992) utilised a vertically orientated grid attached to a vibrating rod which moved the grid in the horizontal axes (x and y). Efforts were made to not only quantify the turbulence generated but to also map the turbulence field across the tank; it was found that the vertical and horizontal components of $\varepsilon$ did not differ to any significant extent. The results of the experiment showed that the increase in turbulence caused a corresponding increase in both copepod suspension and predatory feeding behaviour thought to result from an increase in predator-prey contact rates (Saiz and Alcaraz, 1992).

\section{Stationary grids}

Looking to improve the often-used grid oscillation systems, Warnaars et al. (2006) used a pair of underwater speakers in anti-phase to push water through a stationary grid placed directly in front of each speaker. It was observed that the flow characteristic of the speaker system compared well with grid systems, albeit with lower strain rates making it more representative of natural turbulence fields. Furthermore, $\varepsilon$ is seen to attenuate rapidly with distance from grids in oscillator setups; however, the speaker system generated uniformly distributed $\varepsilon$ throughout the 
entire volume of the tank. It is also noted that the range of turbulence scales observed in grid systems is larger than those measured in the speaker system; when the chlorophyte Selenastrum capricornutum Printz was exposed to the speaker system, growth rate was seen to increase as conditions became more turbulent. This increase in growth was attributed to the fact that the range of $\varepsilon$ experienced by the organisms is more concurrent with the levels in the natural environment. It should also be noted that in the absence of a moving grid, this technique permits direct flow velocity measurements. Due to limitations imposed by equipment practicalities, however, this technique would likely be restricted to nanocosm and microcosm experiments.

\section{Additional case studies}

A number of researchers have used similar gridgenerated turbulence setups to observe predator-prey interactions within turbulent environments (Peters and Gross, 1994; Peters et al., 2002; Dolan et al., 2003; Havskum, 2003; Havskum et al., 2005). For example, Havskum (2003) investigated how grid-generated turbulence affected feeding rates of a predatory dinoflagellate species linking turbulence to the rate of predator-prey interaction. The disadvantage of studies of this nature is that, as well as altering the encounter rate, in many cases the turbulence causes secondary physiological or behavioural changes in the species studied (e.g. Peters and Gross (1994)). When conducting cosm experiments of this nature, it is crucial to use planktonic species that are not sensitive to turbulence; for example, Havskum et al. (2005) observed no change in the autotrophic or mixotrophic growth of the dinoflagellate Fragilidium subglobosum (Stosch) Loeblich III under different turbulence levels but did observe a change in ingestion rates.

In a technique analogous to grid-generated turbulence, Sullivan and Swift (2003) used a pair of vertically oscillating rods to produce varied intensities of turbulence. Interestingly, this paper opposed the commonly held view that dinoflagellates as a group are sensitive to turbulence; out of the 10 species tested, 7 were unaffected by natural levels of turbulence. In a similar departure from vertically oscillating grids, researchers at the Marine Ecosystem Research Laboratory (MERL; Rhode Island, USA) mesocosms made use of a rubberised plunger attached to a vertical pole to simulate tidal mixing. The plunger itself was situated $1 \mathrm{~m}$ above the sediment-laden floor to provide realistic levels of tidal sediment resuspension with the system motor timed to providing a mixing cycle mirroring natural tidal oscillations (Santschi, 1985).

Towards the larger scale of mesocosm studies, it is also possible to use grid-generated turbulence in limnocorrals (Nerheim et al., 2002). Studies undertaken as part of the Nutrients and Pelagic Production project (Nejstgaard et al., 2001a, b; Nerheim et al., 2002) encountered difficulties with this approach, however. In order to promote stratification in some of the limnocorrals, freshwater was added to the surface; this resulted in the limnocorrals rising up out of the water as the mean internal water density was now lower than that of the surrounding water. This effect was countered by increasing densities via the addition of salt to the water in the lower parts of the mesocosms. Altering the salinity to this extent in a biological study is not advised as this would alter the phytoplankton community in favour of species that are less sensitive to changes in salinity. Once stratification was established in the NAPP studies, the grid mixing systems were then used to promote an upper mixed layer, while a low-suction airlift pump system (typically used in aquaculture or marine archaeology) promoted "slow circulation" in the upper layer.

\section{Shaker tables}

Shaker systems are used across a multitude of sciences for a variety of applications from agitation of chemicals to the culturing of microbiological organisms. Due to the ubiquity of shaker tables in academic and scientific institutions, it is not unsurprising that they are frequently used to generate artificial turbulence. Furthermore, they typically have discrete settings allowing researchers to generate a broad range of turbulence levels. While some researchers simply use the rpm settings, more rigorous studies quantify the level of turbulence via acoustic Doppler velocimetry or similar. It should be noted that specific turbulence flow patterns generated by shaker tables are difficult to quantify, thus any recorded changes in biological activity is difficult to ascribe to a particular flow characteristic (Warnaars et al., 2006). Shaker tables typically use one of three different motion paths depending on their intended application: orbital 
or rotary shakers; reciprocal shakers; and, gyratory shakers (Fig. 7).

\section{Orbital shakers}

Orbital shakers (a.k.a. rotary shakers) agitate cultures with a circular motion in the $x-y$ plane (Fig. 7a). Depending on the manufacturer of the shaker, the orbit oscillation is fixed at a set distance or can be altered accordingly. Zirbel et al. (2000) used orbital shakers to observe changes in dinoflagellate morphology over time. Trials were conducted with the shakers set on $40 \mathrm{rpm}$ to $120 \mathrm{rpm}$ before a rate of $75 \mathrm{rpm}$ was designated as "relatively mild" turbulence. It is noted that for such shaker experiments, turbulence occurs due to wall effects within the vessel. This has two ramifications: firstly, the turbulence will increase with proximity to the vessel walls and secondly, the vessel needs to be of a suitable size to allow turbulent mixing to impact upon fluid in the centre (Peters and Redondo, 1997). Orbital shakers typically promote the central "doldrum," or dead-space, region in flasks marked by minimal in situ turbulence meaning that the cells are no longer being cultivated under near-isotropic conditions (Juhl et al., 2000). Furthermore, the turbulent mixing produced would be predominantly horizontal with a weak secondary vertical component. However, horizontal eddy diffusivity in the ocean is thought to be "several orders of magnitude" greater than the vertical equivalent [Okubo (1976) cited in Estrada et al. (1987)].

As shaker table experiments typically make use of available apparatus, there is often a range of different sized and shaped vessels used which makes comparisons between studies difficult. In a comparative study between turbulence generated by grids versus that generated by orbital shakers, Guadayol et al. (2009b) trialled a number of different shaker setups with different periods of oscillations as well as various volumes and flask (Florence, Nalgene and Erlenmeyer) types. The research showed that at high levels of shaking, the turbulence field remains isotropic independent of volume or flask shape. However, at lower levels of $\varepsilon\left(<10^{-8} \mathrm{~m}^{2} / \mathrm{s}^{3}\right)$, the isotropy began to fall, probably as a result of lower signal-to-noise ratios (SNR) in the Doppler velocimeter as well as the fluid approaching the laminar-turbulent transition point. Furthermore, orbital frequencies of $<1 \mathrm{~Hz}$ are not recommended as it at approximately this frequency that the laminar-turbulent transition occurs in flasks. As orbital shaker turbulence is generated via wall friction, $\varepsilon$ decreases with distance from the sides and bottom; an order of magnitude decrease in $\varepsilon$ was observed in measurements when transitioning from the wall to the centre of the flask. Thus, it is recommended that "small and narrow" vessels (e.g. Nalgene flasks) be used to limit this effect as much as possible (Guadayol et al., 2009b).

\section{Reciprocal shakers}

Reciprocal shakers oscillate from side to side along a single axis in the $\mathrm{x}$ - or y plane (Fig. 7b). The length along which the oscillation occurs can be altered accordingly with longer lengths equating to higher levels of turbulence (Juhl et al., 2000). The advantage of reciprocal shakers is the removal of the central doldrum in the flasks which typically occurs in orbital shakers. In a comparative study of the effects of shaker table-generated mixing relative to Couette-generated shear flow, Juhl et al. (2000) subjected populations of the dinoflagellate Lingulodinium polyedra (F. Stein) J.D. Dodge to different durations of constant mixing. Actually, reciprocal tables allow standing waves to form in the flask, resulting in an oscillating fluid surface that ensures all cells in the population

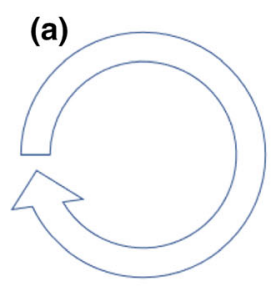

Fig. 7 Motion paths of vessels placed on different types of shaker tables as seen from above. a) An orbital/rotary shaker oscillates in a circular motion in the $\mathrm{x}-\mathrm{y}$ plane. $\mathrm{b}$ ) A reciprocal (b)

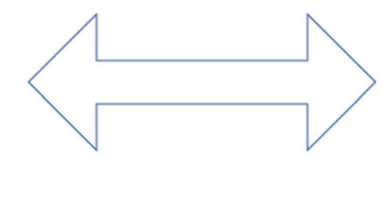

(c)

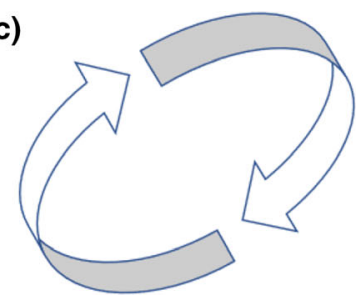

shaker oscillates from side to side along a single axis. c) A gyratory shaker oscillates vessels in a circular motion with both horizontal and vertical components to the motion 
experience variable mixing. While the level of turbulence was not quantified directly, attempts were made to approximate mixing via a comparison of the qualitative outcome between the shaker populations and the Couette populations; the response of the cells exhibited a similar response in both setups.

\section{Gyratory shakers}

As well as orbital shakers and reciprocal shakers, there are also gyratory shakers which oscillate vessels in a circular motion with both horizontal and vertical components to the motion (Fig. 7c). An experiment was carried out to observe effects of gyratory-shakergenerated turbulence (as well as of growth medium, fluid depth, tank material and initial cell concentration) on the doubling time of the protozoan Tetrahymena sp. (Hellung-Larsen and Lyhne, 1992). It was noted that gyrational shaking resulted in a circular wave that propagated around the edge of the shaking vessel. The study showed that the doubling time was increased (i.e. cell division decreased) with shaking but the impact of the shaking reduced with increased fluid depth. Morphologically, cells that were exposed to shaking exhibited less-prominent nuclear membranes and the development of small granules inside the cell cytoplasm. It was also observed that viscosity played a role as the effect of shaking on cell division was reduced when dextran was added to increase the viscosity of the medium; clearly, the increase in viscosity acted to reduce the overall level of turbulence in the vessels. The study also compared the impact of gyratory agitation to reciprocal shaking and bubbling; when using gyrational shaking, the impact of shaking rate on cell division was seen to be dependent on initial cell concentration, but this was not so for reciprocal shakers (Hellung-Larsen and Lyhne, 1992).

\section{Additional case studies}

Building upon early work regarding the mass culture of algae, Fogg and Than-Tun (1960) used a shaker apparatus to ascertain the optimum shaking speed to maximise cultures of Anabaena cylindrica Lemmermann. Even low agitation speeds were seen to increase cell growth compared to unshaken cultures. While moderate shaking was seen to increase growth due to increased suspension and nutrient flux, if the shaking rate exceeded $140 \mathrm{rpm}$, the cell growth rate showed no increase when compared to unshaken cultures. Opposing these findings, Tuttle and Loeblich (1975) attempted to find the optimal growth conditions for the dinoflagellate Crypthecodinium cohnii (Seligo) Chatton and observed exponential death rates of cells at both 40 and $80 \mathrm{rpm}$; these early results hinted at the turbulence sensitivity of some dinoflagellate species.

In what has now become a classic paper in the study of phytoplankton-turbulence interaction, White (1976) used rotary shakers to agitate cultures of Alexandrium tamarense (Lebour) Balech to note the effect on cell growth while investigating the cause of red tides in Eastern Canada. Results show that cell growth reduced rapidly at high levels of continuous shaking; even intermittent shaking and/or shaking at low speeds was seen to adversely affect cell growth. As well as mechanical destruction, White (1976) attributed the decreased growth rate to cell disorientation that caused subsequent interference with phototactic migration. Peters and Marrasé (2000) have since estimated the turbulence generated in this study to be higher than natural $\varepsilon$ with values between $4.30 \times 10^{-3}$ and $1.19 \times 10^{-2} \mathrm{~m}^{2} / \mathrm{s}^{3}$. While the White (1976) study made no attempt at turbulence quantification (it was, after all, at the time seen as a purely biological study), it none-the-less sparked interest in turbulence studies within the marine ecological community.

Clearly drawing upon these findings, Berdalet (1992) sought to identify the mechanism(s) by which cell growth is reduced in turbulence. Cultures of the $\mathrm{HAB}$ dinoflagellate Akashiwo sanguinea (K. Hirasaka) Gert Hansen \& Moestrup were exposed to shaker table turbulence with cellular volume, shape and location of nuclei, RNA and DNA concentrations all recorded. Berdalet (1992) postulated that the observed reduction in growth was a result of the physical disruption of chromosome separation during cell division. Again $\varepsilon$ was unquantified in this study (Peters and Marrasé (2000) later estimated the corresponding $\varepsilon$ as $2 \times 10^{-3} \mathrm{~m}^{2} / \mathrm{s}^{3}$ ), but more recent studies based on the same experimental setup utilised an acoustic Doppler velocimeter to record water speed at different points in the flask (Berdalet et al., 2007). Of relevance within the current review is a thorough literature overview of all experiments on turbulencedinoflagellate interactions which, as per Peters and Marrasé (2000), includes estimates for $\varepsilon$ calculated 
using experimental setup data from individual experiments (see Appendix 3-Supplementary Material).

\section{Aeration systems}

When biologists look to cultivate cells, they often seek to aerate the water via a bubble stone at the base of the tank which allows gases (e.g. $\mathrm{CO}_{2}$, oxygen) to diffuse into the water, promoting growth. As such, bubble plumes and aeration systems in the lab are a tried and tested technique for mixing water and aerating growth tanks. Furthermore, most microbiological laboratories have access to air compressors and piping to facilitate the use of aeration systems. A by-product of this aeration is that the bubbles themselves break down any stratification, thereby homogenising the water while also advecting the cells as the central bubble plume effectively promotes formation of a toroidal convection cell in the tank. Within the mesocosm community, aeration systems are typically seen to be gentler in their approach to turbulence generation due to their absence of moving parts that have the potential to mechanically damage organisms (Sanford, 1997; Striebel et al., 2013).

In laboratory setups, it can be difficult to determine whether the change in growth rate is a result of the turbulence induced by the bubble flow or as a result of atmospheric gases being entrained through the water. How the culture will react is species-dependent with dissolved oxygen being required for respiration, while $\mathrm{CO}_{2}$ promotes photosynthesis. Gas addition can also result in a change in $\mathrm{pH}$ via $\mathrm{CO}_{2}$-induced decreases in the $\mathrm{pH}$ of water; this can have impacts for $\mathrm{pH}$-sensitive species (Havskum and Hansen, 2006). An unintended side-effect of bubbler aeration systems is a temperature change to the fluid medium. As gases that are introduced to the fluid are typically at air temperature, this can impart additional thermal energy to the system. Furthermore, as the gas has typically undergone pressurisation prior to release, there may also be associated adiabatic thermal effects.

Båmstedt and Larsson (2018) noticed an aggregation of bacteria, algae and detritus at the water surface of their unmixed cosms during experiments. This was thought to be the result of surface heating from the overhead irradiance lamps causing a thermal lid effect in the upper $60 \mathrm{~cm}$. It was found that bubbling at a rate of $1 \mathrm{~Hz}$ from $2 \mathrm{~cm}$ depth was sufficient to break up the surface aggregation, but some mixing was required to break the thermal lid. As such, a comparison between bubbling and surface mixing using fans angled at $45^{\circ}$ to the surface was carried out; overall fan mixing was found to mix the mesocosm faster than bubbling. It should be taken into consideration that the bubbler system was set to emit a single $18 \mathrm{~mm}$-diameter bubble at $1 \mathrm{~Hz}$ so as to not cause any undesirable aeration effects.

In an attempt to determine the optimal conditions for cultivating the dinoflagellate Crypthecodinium cohnii, Tuttle and Loeblich (1975) subjected cultures of cells to agitation by aeration (as well as magnetic stirrers and shaker tables). Sterilised air was bubbled through the medium at a rate of $1.8 \mathrm{~L} / \mathrm{min}$; the increase in observed growth rate was negligible. In a series of experiments exploring potential biomass species, Thomas et al. (1984a, b, c) used aeration systems to "vigorously" aerate and mix the cell cultures. Using a gas mix of $1 \% \mathrm{CO}_{2}$ in air, two aeration pipes were placed at the bottom of the tank and gas supplied at a rate of $2000 \mathrm{ml} / \mathrm{min}$. The researchers reported "very high densities" and reported no evidence of mechanical damaging of the cells despite the high aeration rate. There was no control tank setup nor any attempt to quantify the turbulence produced. Again, with reference to the commercial cultivation of phytoplankton, Aguilera et al. (1994) used bubbler agitation in chemostats to mix cultures of a microalga. Novel in this experiment was an attempt to quantify mixing in terms of mechanical energy supplied to the system calculated using standard physical equations relating gas pressure, velocity, and the conservation of mass and/or energy. Within this work, the role of turbulence was recognised in preventing sedimentation, promoting a homogenous distribution of cells and nutrients, and increasing the nutrient supply to the surface of the cell. However, agitation by bubbles was also cited as a way by which gases are more efficiently diffused into the medium. As discussed earlier, this effect of increased gas diffusion on cell growth would be difficult to distinguish from changes due to the increase in turbulence.

Aeration systems have been used to good effect for studying natural planktonic communities (Eppley et al., 1978; Sonntag and Parsons, 1979). As part of the Controlled Ecosystem Pollution Experiment (CEPEX), Sonntag and Parsons (1979) used aeration to simulate upwelling, then added salmonids to create an additional trophic layer that would ordinarily be 
absent (the enclosures were taken to depth by divers and then slowly raised so any suitably motile organism would have been able to escape). The study recorded high rates of phytoplankton sedimentation suggesting that the aeration regime chosen was insufficient to promote resuspension. Using the same limnocorrals, Nerheim et al. (2002) combined grid-generated turbulence with an aeration system to study a natural food web. Researchers quantified the rate of vertical mixing via a dye dispersion study; this led them to realise that the vertical eddy diffusivity was $0.06 \mathrm{~cm}^{2} / \mathrm{s}$, lower than the expected value outside of the enclosures (Steele et al., 1977). It was thus postulated that the presence of the enclosures reduced the horizontal mixing and as this is coupled to vertical mixing, there was a subsequent impact on vertical mixing also. Efforts were made to limit daily mixing to the level just required to break any measured stratification; however, no efforts were made to quantify this vertical mixing. Microscopic analysis of the species within the enclosures verified that the bubbles did not damage cells mechanically, with Eppley et al. (1978) reporting "no grossly unnatural results".

\section{Couette cylinders}

Named after French physicist Maurice Couette who first used them in 1890 (Couette, 1890), this equipment generates shear flow in a small gap between two concentric cylinders. A fluid medium is placed in the gap between the smaller inner cylinder and the larger outer cylinder. The inner cylinder then rotates at a given speed producing uniform flow conditions (Peters and Redondo, 1997; Sullivan and Swift, 2003). A key advantage of this setup is that shear flow can be easily calculated from angular velocity, thereby removing the need for physical measurements to calculate flow parameters. Furthermore, a variety of different forms of turbulence can be produced by rotating the cylinders at different velocities relative to each other. However, Sullivan and Swift (2003) reported that the turbulence produced by Couette cylinders is intrinsically unrepresentative of natural turbulence because it applies constant shear both temporally and spatially.

Some of the first phytoplankton-turbulence studies were carried out using Couette cylinders. Pasciak and Gavis (1975) conducted a series of experiments on the effect of turbulence on nutrient uptake rate in diatoms.
Interestingly, they compared the uptake rate between cell cultures on orbital shaker tables to those inside a Couette flow. While the shear flow rate was calculated for the Couette flow, no attempt was made to quantify the turbulence generated inside the flasks on the shaker table. Building upon this work, Thomas and Gibson (1990a,b) used an almost identical setup to observe the impact of shear flow on nutrient uptake on Lingulodinium polyedra, a HAB-forming dinoflagellate species. Using a series of Couette cylinders with rotational speeds ranging from $1 \mathrm{rpm}$ up to $60 \mathrm{rpm}$, the researchers calculated various turbulent parameters using the rotational speed.

Using a similar Couette setup, Juhl et al. (2000) also conducted an investigation on the dinoflagellate, Lingulodinium polyedra. The aim of this experiment was to account for the variability in studies by measuring the effect of turbulence on population growth under varying light-dark cycles, differing light levels and different stages of the cell cycle. The outcomes highlighted a number of key mechanisms: (a) that cell growth rate decreased more when flow was applied in the last hour of the dark phase as compared to applying it to illuminated cultures; (b) populations cultured in lower light conditions experienced proportionately lower growth rates when exposed to flow than those cultured in higher light conditions and (c) older cultures in the late exponential phase experience higher mortality under flow than cells in the early phase. A key outcome of this study was that the extent to which turbulence affects the cell population is not only light-dependent but also depends on the physiological state of the cell (and the phase of its life cycle).

Juhl et al. (2000) also compared the outcomes of the Couette studies to equivalents carried out using turbulence generated using shaker tables. Unfortunately, the shaker table turbulence was unquantified; however, attempts were made to approximate the shear flow via a qualitative comparison of results. It should be noted that Warnaars et al. (2006) recognised that the minimum strain rate used in the studies of Thomas and Gibson (1990a,b) were up to two orders of magnitude greater than those observed in the natural environment.

A summary of turbulence generation methods and associated advantages and disadvantages can be found in Table 3, along with example references highlighting best practice for each of the main techniques. 
Table 3 Summary table of commonly used turbulence generation techniques

\begin{tabular}{|c|c|c|c|}
\hline Technique & Pro & Con & Example \\
\hline $\begin{array}{l}\text { Oscillating } \\
\text { Grids }\end{array}$ & $\begin{array}{l}\text { Can be configured for near-isotropic turbulence } \\
\text { Reduction in resuspension (horizontal grids) } \\
\text { Can use mesh screens to create refuge area }\end{array}$ & $\begin{array}{l}\text { Obstructs flow velocity measurement equipment } \\
\text { Risk of mechanical damage to organisms } \\
\text { Steep turbulence gradients; } \varepsilon \text { highest near grid } \\
\text { but decays rapidly with distance }\end{array}$ & $\begin{array}{l}\text { Schapira } \\
\text { et al. } \\
(2006)\end{array}$ \\
\hline $\begin{array}{l}\text { Shaker } \\
\text { tables }\end{array}$ & $\begin{array}{l}\text { Low-cost, off-the-shelf equipment } \\
\text { Commonly found in laboratories }\end{array}$ & $\begin{array}{l}\text { Typically restricted to small volumes } \\
\text { Turbulence generated is non-isotropic with high } \\
\varepsilon \text { near flask wall decreasing towards centre }\end{array}$ & $\begin{array}{l}\text { Berdalet } \\
\text { et al. } \\
(2007)\end{array}$ \\
\hline $\begin{array}{l}\text { Aeration } \\
\text { systems }\end{array}$ & $\begin{array}{l}\text { Can be applied across all scales of cosm } \\
\text { Commonly found in microbiological laboratories } \\
\text { Possible to use equations to estimate turbulence from } \\
\text { energy input }\end{array}$ & $\begin{array}{l}\text { Introduction of gases causing secondary growth } \\
\text { effects in cells } \\
\text { Bubbles can cause adiabatic thermal effects and } \\
\text { impede flow velocity measurements } \\
\text { Not quantifiable turbulence }\end{array}$ & $\begin{array}{l}\text { Aguilera } \\
\text { et al. } \\
\text { (1994) }\end{array}$ \\
\hline $\begin{array}{l}\text { Couette } \\
\text { cylinders }\end{array}$ & $\begin{array}{l}\text { Shear flow can be calculated from angular velocity, } \\
\text { removing the need for physical measurements }\end{array}$ & Turbulence unrepresentative of natural systems & $\begin{array}{l}\text { Stoecker } \\
\text { et al. } \\
(2006)\end{array}$ \\
\hline
\end{tabular}

Based on this review, it is recommended that oscillating grids become the turbulence generation standard; of the techniques evaluated, the grid-generated turbulence is closest to that found in natural systems. Furthermore, it is relatively easy to adjust the experimental setup in order to facilitate species across different groups and, on a broader topic scale, across the different marine science sub-disciplines. This technique is also the most commonly used (Table 1), thereby facilitating easy comparisons with any future study. See Appendix 1-Supplementary Material for a summary of lesser-used techniques for generating turbulence including pumping, magnetic stirrers, rotating chambers, wave tanks, impellors/propellers, paddles, dialysis cylinders and convective mixing.

\section{Methods for quantifying turbulence}

It is crucial to properly describe the nature and quantify the magnitude of the turbulent environment within a cosm. To relate a cosm experiment back to its intended real-world application, organisms should be exposed to turbulence that mirrors natural turbulence as closely as possible. While some studies simply use the rate of motor revolutions as a proxy for turbulence quantification, others use an array of techniques to maintain turbulence requirements. It should be noted that a majority of turbulence generation techniques involve the placement of movement apparatus in the test tanks (e.g. grids); as a result, it becomes difficult to place sensors for turbulence measurement undisturbed in the tank as well.

Instead of measuring turbulence directly, some researchers simply consider the mechanical energy input to the cosm (Kiørboe et al., 1990; Aguilera et al., 1994; Martínez et al., 2017). For example, in a gridgenerated turbulence study, Kiørboe et al. (1990) was able to calculate $\varepsilon$ as a function of power input from the motor as $\varepsilon=W / V \times 1 / \rho$, where $\mathrm{W}=$ power input (W), $\mathrm{V}=$ volume of fluid $\left(\mathrm{m}^{3}\right)$ and $\rho=$ density of fluid $\left(\mathrm{kg} / \mathrm{m}^{3}\right)$. While easily calculated, these values are often theoretical and can be presented without proper calibration. Given the ad hoc nature of many turbulence experiments, this estimate of $\varepsilon$ (and associated calibration) must be considered on a case-by-case basis (Guadayol et al., 2009b). Furthermore, it also makes comparison between different studies difficult as this $\varepsilon$ value is not standardised nor easily comparable to natural systems.

The following section provides an overview to the various techniques used to quantify turbulence as well as any corresponding advantages and/or disadvantages. Methods reviewed include particle tracking velocimetry, particle imaging velocimetry, planar laser-induced fluorescence, Doppler velocimetry, and 
calculation via empirical formulae. Figure 8 shows a breakdown of how frequently various methods have been used for turbulence quantification.

\section{Particle tracking velocimetry}

As a precursor to digital image analysis techniques, early particle imaging was carried out using video recorders attached to microscopes [e.g. Saiz and Alcaraz 1992)]. This technique involves the direct imaging of individual tracer particles (e.g. reflective spheres or phytoplankton cells) highlighted by a sheet of laser light. An image is taken and compared to another image taken some small time period later. The subsequent direct image comparison allows for local particle displacement to be determined. By accounting for the time delay and image magnification, it is possible to map the velocity field of a tank. While this analysis has proven to be computationally expensive, it does result in a high vector density with good accuracy and spatial resolution (Webster et al., 2001). The image field is then divided into a grid, the instantaneous velocities are decomposed into horizontal and vertical components, the spatial means within a grid cell are computed. This spatial mean is then subtracted from the instantaneous velocity field to yield the fluctuating component of the particle velocities, which is representative of the turbulence in the flow, and, from this, the turbulent dissipation rate can be determined (Marrasé et al., 1990; Saiz and Alcaraz, 1992).

Technological advances in velocimetry are now permitting fluid dynamicists to measure the flow fields across illuminated planes within a cosm. As water is a transparent medium, these techniques typically involve the illumination of particles suspended in the fluid, as suspended sediment, planktonic organisms or artificially introduced reflective particles. These particle tracking velocimetry techniques typically involve an external source of illumination (e.g. a light or laser) and an external camera. Thus, a benefit of these techniques is that they do not require apparatus to be placed in the test tank; hence, they can be used with a variety of turbulence generation methods. While advances in particle tracking velocimetry now permit detailed imaging of 3D flows (Hoyer et al., 2005; Raffel et al., 2018), this has yet to be applied to any bio-turbulence studies which, to date, have not progressed beyond two-dimensional (2D) imaging. This technique is sometimes referred to as digital particle tracking velocimetry (DPTV) (Webster et al. (2001).

\section{Digital particle imaging velocimetry}

Digital particle imaging velocimetry (Digital PIV or DPIV) involves seeding the test fluid with highly reflective neutrally buoyant particles. The size of the
Fig. 8 Methods used to quantify turbulence in the publications reviewed. Particle tracking: refers to particle tracking velocimetry, DPIV and PLIF. Doppler velocimetry: refers to ADV and LDV. Other: refers to dye dispersion and bioluminescence

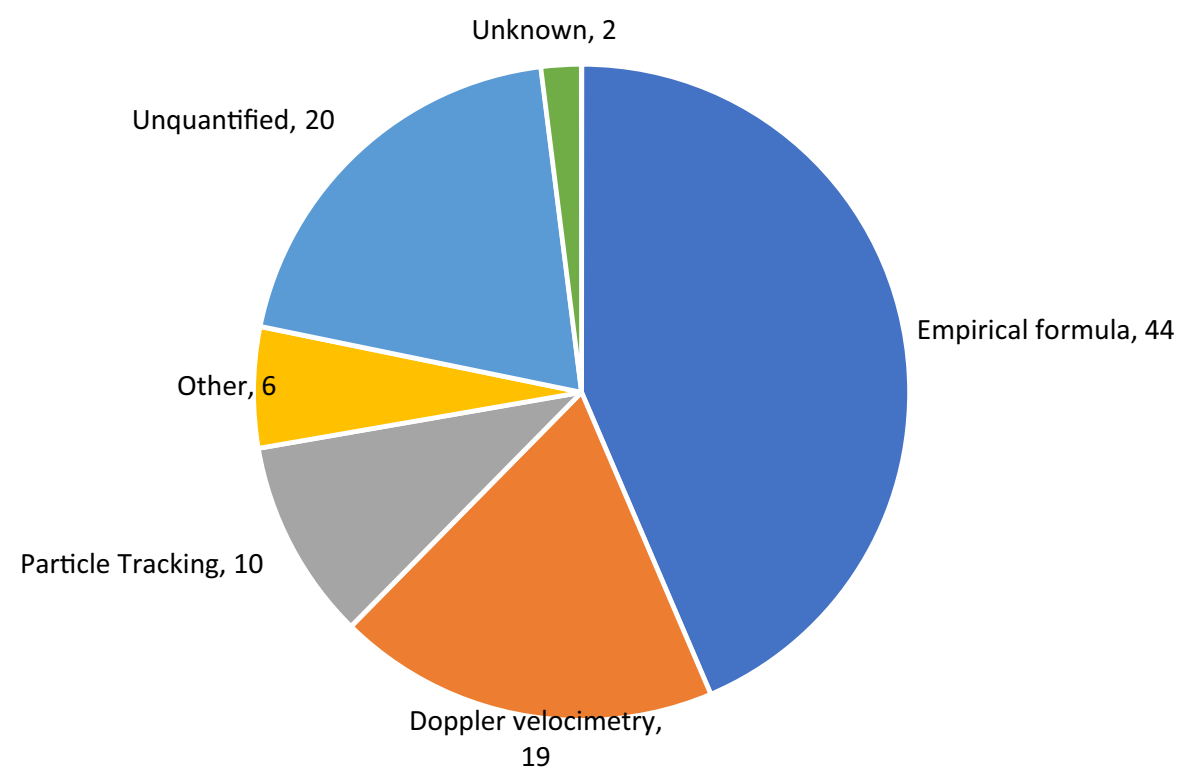


particles required is dependent on the size of the fluid structures required by the study. A laser light sheet is then projected into the tank resulting in an illuminated plane. This laser is synchronised to a digital camera positioned perpendicular to the illuminated plane which photographs the particle movement; this allows a velocity map of fluid motion to be produced. It is important to select a suitable laser pulse and shutter speed to prevent signal distortion and other artefacts (Zirbel et al., 2000). Older DPIV systems required the simultaneous use of two digital camera and corresponding laser sheets to image 3D flow; this required unimpeded access to different sides of the cosm (Eder et al., 2001). Fortunately, more modern techniques (e.g. tomographic PIV; tomo-PIV) have streamlined the measurement of $3 \mathrm{D}$ and time-resolved (fourdimensional) flows with both overall precision and higher spatial resolution (Scarano, 2012; Raffel et al., 2018). Calculation of $\varepsilon$ using PIV can be a mathematically complex procedure. Assuming the turbulence is both isotropic and homogeneous, Xu and Chen (2013) simplify the estimation of $\varepsilon$ :

$\varepsilon=15 v\left\langle\left(\frac{\partial u^{\prime}}{\partial x}\right)^{2}\right\rangle$

where $\langle\cdot\rangle$ denotes a mean average, $v=$ kinematic viscosity $\left(\mathrm{m}^{2} / \mathrm{s}\right)$, and $u^{\prime}=$ velocity fluctuations in the $\mathrm{x}$ direction with $u^{\prime} \equiv u-u$ and $u$ being the X-component velocity $(\mathrm{m} / \mathrm{s})$.

The introduction of lights and lasers into the fluid medium does have the potential to influence the behaviour of the test organisms. Phototaxic phytoplankton species that use light to orientate their swimming direction could be drawn towards the laser light. Furthermore, high-intensity lasers could in theory cause photoinhibition in photosynthetic organisms and reduce the rate of primary production. Motile phototactic species could also be influenced; however, Linares (2015) observed in a turbulence experiment designed to specifically study the potential for laserinduced photoinhibition, that "laser exposure has little effect on phytoplankton".

While it is standard practice to add tracer particles to the test medium to increase the SNR (Estrada et al., 1987; Fraisse et al., 2015), it is important to select an appropriate tracer. The motion of any tracer is assumed to follow the flow dynamics of a setup; the extent to which the tracer particles accurately follow the flow can be determined via the Stokes number. The test tracer should have a Stokes number $\ll 1$ in order for the tracers to mirror the fluid movement; a Stokes number $<0.1$ will ensure an accuracy of $99 \%$ (Tropea and Yarin, 2007). A tracer should also be neutrally buoyant and sized appropriately; a smaller diameter is preferable but should be large enough to be recorded. The tracer selected should be reflective so as to scatter the incident laser light; Webster et al. (2001) reported titanium dioxide particles have a superior reflectance to comparably sized nylon bead tracers or kaolin. Organic substances such as Lycopodium pollen grains (Saiz and Kiørboe, 1995) and rheostatic fluid (made from fish scales (Latz et al., 1994; Hondzo et al., 1997) can also be used as tracers, though the addition of extra organic matter and its subsequent decomposition could influence growth rates. As such, tracers are normally added to cosms absent of test organisms. If a tracer is added to a tank containing organisms, it should be both non-toxic and non-influential on growth rates. For environmental reasons, it is prudent to avoid the use of microplastics; if the chosen tracer is a plastic, the particles should be recovered before disposal.

\section{Planar laser-induced fluorescence}

PLIF is similar to DPIV but makes specific use of the fluorescent properties of phytoplankton. As with DPIV, a laser sheet is introduced into the fluid medium to illuminate a 2D cross-section with the cosm. Phytoplankton cells are seen to have inherent fluorescent properties due to the presence of chlorophyll compounds and other photosynthetic cellular organelles. As such, phytoplankton cells are known to exhibit a peak absorption wavelength of light at $440 \mathrm{~nm}$. Following absorption, the light is subsequently re-emitted as a lower energy photon at $685 \mathrm{~nm}$ manifesting itself as fluorescence (Leeuw et al., 2013). It is possible to calibrate this fluorescence intensity to attain cell concentration as well as directly measure the velocities of individual cells akin to DPIV (Liu et al., 2017). Interestingly, as technology has progressed the robustness of PLIF systems has increased to the point where these systems can be deployed directly in the field, allowing researchers to obtain in situ measurements on fluorescent particle distributions (Franks and Jaffe, 2008). As an extension of PLIF, 3D laser-induced fluorescence (3D LIF) 
technology exists that is able to reconstruct a 3D frozen-field image of a fluid flow by scanning perpendicular to the 2D laser sheet (Crimaldi, 2008); to date, no evidence could be found of it being applied to bio-turbulence studies. Despite the differences in technology, quantification of turbulence based on DPIV and PLIF draws upon the same calculations.

Relying on fluorescence does mean that any other photoactive particles and/or chemicals in the fluid medium will obscure the fluorescent signature. In particular, the presence of CDOM can preferentially absorb certain light wavelengths and attenuate light transmission through the water. The fluorescence intensity from certain dyes are also dependent on the $\mathrm{pH}$ and temperature of the water (Crimaldi, 2008), so this should be corrected for to allow comparisons between studies. Also of note is the process of photobleaching by which the fluorescent intensity of a dye or phytoplankton cell diminishes over time with prolonged exposure to high-intensity light of certain wavelengths; selection of a suitable dye should prohibit these effects but dyes that are less susceptible to photobleaching are typically more costly (Crimaldi, 2008).

\section{Doppler velocimetry}

Doppler velocimetry involves introducing a soundwave or laser of known frequency into a fluid medium. This beam is then reflected off moving particles within the fluid causing a measurable frequency shift. Doppler velocimetry allows the user to accurately measure 3D mm-scale velocities within a water body.

\section{Acoustic Doppler velocimetry}

Single-point velocity Acoustic Doppler Velocimeters (ADV) can be used to good effect to measure 3D point velocities. As the name would suggest, ADVs utilise the Doppler effect by which a pulse of sound of a known frequency is sent into the water from a central transducer. This pulse is reflected by particles in the water back to three receivers which calculate the motion of the water from the shifted frequency. The reflective particles in the water can be natural (e.g. sediment, microorganisms) or artificial (e.g. seeded particles in test tanks). The addition of such particles greatly improves the SNR, which is especially useful in quiescent flows.
While the resolution of the instrument varies with manufacturer (as well as sampling rate and sampling volume), one can directly quantify different turbulence parameters with suitable processing by measuring Reynolds stresses (Lohrmann et al., 1995) or by fitting the Kolmogorov $-5 / 3$ slope to the inertial subrange of the velocity spectra (Bluteau et al., 2011). ADVs have many logistical advantages; namely, they provide a relatively simple and inexpensive way to quantify turbulence (Bluteau et al., 2011) while also being portable and robust. Furthermore, they do not require frequent calibration and are not constrained by turbidity as optical sensors are (Lohrmann et al., 1995). As well as bio-turbulence studies, ADVs are commonly used as velocity sensors in physical limnological and oceanographic studies both in the laboratory and in the field.

Building upon a previous study that overlooked the quantification of turbulence (Berdalet, 1992), Berdalet et al. (2007) used a side-mounted Nortek 3D $10 \mathrm{MHz}$ ADV to record current velocities at different points within a test flask placed on a shaker table. Interestingly, the ADV was mounted on the shaker table so was stationary relative to the flask. Sullivan and Swift (2003) used a Sontek ADV to quantify $\varepsilon$ at different positions across a range of turbulent intensities. As with DPIV, the test medium was also seeded with microparticles in order to increase the acoustic backscatter and thus improve the SNR. Sullivan and Swift (2003) used two different mathematical techniques to calculate turbulence from the velocity measurements, providing a comparison of values which showed that the two methods yielded similar results. These researchers went to lengths to ensure that the levels of turbulence generated in the experiments were analogous to those found in the ocean (namely, $\varepsilon=10^{-8} \mathrm{~m}^{2} \mathrm{~s}^{-3}$ for the lower turbulence level and $\varepsilon=10^{-4} \mathrm{~m}^{2} \mathrm{~s}^{-3}$ for the higher) and compared them to published $\varepsilon$ values. A Nortek ADV was used by Guadayol et al. (2009b) to assess the differences in $\varepsilon$ between grid- and shaker-generated turbulence. Depending on the manufacturer, the pronged head of an ADV can have a maximum diameter $\sim 10 \mathrm{~cm}$ in diameter thus limiting the size and shape of vessel in which it is possible to obtain measurements. In order to record the velocity in a small grid-generated turbulence vessel, this study made use of a set of bespoke $2 \mathrm{~L}$ and $15 \mathrm{~L}$ vessels that incorporated the transducer heads into the wall of the 
vessel itself. The vessels were constructed from Delrin plastic to limit the internal reflection from the tank walls. A larger $2500 \mathrm{~L}$ mesocosm tank was constructed with a grid of mesh size $10 \mathrm{~cm}$ so that the ADV could be deployed through the mesh without interfering with the grid mechanism. With regards to measuring velocities in the orbital shaker vessels, a custom-made, side-looking ADV was placed in the vessel, held in place by a posable arm also attached to the shaker as per Berdalet et al. (2007). Also of interest in these studies is the sampling time requirements; a longer sampling time is needed in larger vessels to resolve larger overturns. Thus, a minimum duration of $10 \mathrm{~min}$ was used in the grid tanks and $5 \mathrm{~min}$ for the shaker tables.

\section{Laser Doppler velocimetry}

Optical Laser Doppler Velocimeters (LDV) can be used in a manner similar to acoustic Doppler velocimetry. The fluid medium is seeded with reflective beads in order to increase the SNR and then the laser is used to image particle motion within the fluid. Usefully, the technology has now advanced to the point where it is now readily commercially available with an easy installation. Unlike DPIV, only a single system is need to image 3D flows (Eder et al., 2001). Due to the use of lasers and seeded water, this method has been incorrectly referred to as DPIV in some literature; however, similar considerations regarding the introduction of laser beams to water and the addition of seeded particles discussed should be applied.

In situations where it is difficult to place the sensor in the tank directly (due to size or presence of other apparatus), it is possible to image the fluid motion from outside the tank if the vessel is transparent and taking into account any inherent refractive effects. Peters and Gross (1994) mitigated this lensing effect by constructing a replica test tank solely for turbulence quantification. The replica tank was built out of transparent acrylic; it was surrounded by a second, square acrylic tank which was then filled with water. The outer layer of water surrounding the test tank reduced the ratio of refractive indices, thereby reducing the effects of refraction. The test tank was seeded with rutile (a mineral of titanium oxide) spheres of 2 to $3 \mu \mathrm{m}$ diameter and particle velocities were measured in the $u$ and $v$ directions via a 2-axis laser anemometer.
A summary of the pros and cons associated with each method discussed in this section can be found in Table 4.

\section{Empirical formulae}

Empirically derived formulae are used in $44 \%$ of publications to quantify turbulence (Fig. 8), reflecting the high proportion of studies using Couette cylinders and shaker tables. In circumstances where the cosm is either too small or unsuitable to use measurement apparatus, it is possible to approximate the level of turbulent intensity using basic measurements of the experimental setup. This may be useful for researchers that do not have access to the high-cost, specialist measurement apparatus discussed previously. It is recommended to report turbulence quantification as dissipation rates $\left(\varepsilon ; \mathrm{m}^{2} / \mathrm{s}^{3}\right)$ to be concurrent with physical oceanographic observations in the field and thus facilitate comparison between studies. As such, Eqs. (3) and (5) below have been modified to output in $\mathrm{m}^{2} / \mathrm{s}^{3}$.

\section{Shakers}

Due to their small size and vessel motion, shaker experiments have typically precluded direct fluid measurement (the exception being Zirbel et al. (2000) who used PIV). As such, Peters and Marrasé (2000) were able to retrospectively estimate $\varepsilon$ in a number of studies:

$\varepsilon=\frac{S(d \cdot f)^{3}}{V}$

where $d=$ distance the vessel travels in one oscillation (m); $f=$ frequency of oscillation $(\mathrm{Hz}), V=$ volume of fluid $\left(\mathrm{m}^{3}\right)$, and $S=$ surface in contact with fluid (as derived from flask geometry; $\mathrm{m}^{2}$ ). The resultant $\varepsilon$ value will be indicative of the order of magnitude of $\varepsilon$, not a direct equality due to approximation in turbulent length scales.

Building upon this, Guadayol et al. (2009b) empirically formulated a relationship for $\varepsilon$ based on direct velocity measurements across different frequencies of oscillation and orbit diameter:

$\varepsilon=10^{(-5.03-1.56 \phi+f(1.71+1.08 \phi))-5}$ 
Table 4 Summary table of different turbulence measurement techniques

\begin{tabular}{|c|c|c|}
\hline Technique & Pro & Con \\
\hline $\begin{array}{l}\text { Particle tracking } \\
\text { velocimetry }\end{array}$ & $\begin{array}{l}\text { High accuracy and spatial resolution } \\
\text { External to tank }\end{array}$ & $\begin{array}{l}\text { Redundant technology with the advent of more powerful } \\
\text { CPUs and digital cameras }\end{array}$ \\
\hline DPIV & $\begin{array}{l}\text { External to tank } \\
\text { Produces velocity fields over the full field of } \\
\text { view of the camera }\end{array}$ & $\begin{array}{l}\text { Can be difficult to set up } \\
\text { Equipment setup can be very costly } \\
\text { Potential for introduction of microplastics into water ways } \\
\text { Refraction effects need to be accounted for } \\
\text { Requires access to the tank from at least two directions } \\
\text { Requires two sets of equipment to visualise flows in 3D } \\
\text { Complex, highly technical experimental setup }\end{array}$ \\
\hline PLIF & $\begin{array}{l}\text { Can map cell concentrations as well as } \\
\text { velocities } \\
\text { Can be deployed in the field in situ } \\
\text { External to tank } \\
\text { Produces velocity fields over the full field of } \\
\text { view of the camera }\end{array}$ & $\begin{array}{l}\text { Can cause photobleaching in cells } \\
\text { Refraction effects need to be accounted for } \\
\text { Complex, highly technical experimental setup }\end{array}$ \\
\hline ADV & $\begin{array}{l}\text { Portable and robust } \\
\text { Can be used in turbid water } \\
\text { Possible to obtain multiple turbulence } \\
\text { characteristics }\end{array}$ & $\begin{array}{l}\text { Difficult to use in tanks with moving parts } \\
\text { Only point measurements }\end{array}$ \\
\hline LDV & $\begin{array}{l}\text { Simple installation and use } \\
\text { External to tank }\end{array}$ & $\begin{array}{l}\text { Refraction effects need to be accounted for } \\
\text { Equipment setup can be very costly } \\
\text { Potential for introduction of microplastics into water ways } \\
\text { Only point measurements }\end{array}$ \\
\hline
\end{tabular}

where $\phi=$ orbit diameter $(\mathrm{cm})$. Note that Eq. (3) only holds for orbital diameters between 1.4 and $3.0 \mathrm{~cm}$ and oscillation frequencies between 1.19 and $2.54 \mathrm{~Hz}$.

\section{Vertical grids}

With regards to turbulence generated by vertically oscillating grids, $\varepsilon$ can be estimated as a function of grid oscillation frequency, stroke length and cosm dimensions (Peters and Marrasé, 2000).

$\varepsilon=\left(\frac{1}{T / 4}\right) \int_{0}^{T / 4} \frac{0.7 \cdot A_{\text {grid }}}{V} u(t)^{3} d t$

where $T=$ period of one oscillation (s), $A_{\text {grid }}=$ solid area of the grid $\left(\mathrm{m}^{2}\right)$, and $u(t)=$ vertical grid velocity $(\mathrm{m} / \mathrm{s})$, as calculated from oscillation frequency and stroke length. The 0.7 coefficient is the empirically derived drag coefficient of a falling grid (Peters and
Marrasé, 2000). Note that this coefficient will change accordingly with different grid geometries and configurations; given the ad hoc nature of many turbulence studies, a prudent course of action would be to calculate the drag coefficient for different grid setups.

Guadayol et al. (2009b) have also developed a series of empirical equations to describe the $\varepsilon$ at different locations in a tank with a vertically oscillating grid. Equation (5) calculates $\varepsilon$ at a location outside of the grid motion area:

$\varepsilon=2 \times 10^{-6} \cdot s^{9 / 2} \cdot M^{3 / 2} \cdot z^{-4} \cdot f^{3}$

where $s=$ stroke length $(\mathrm{cm}), M=$ mesh size $(\mathrm{cm})$, and $z=$ distance from the centre of the oscillation (cm). Equation (5) holds for stroke lengths between 2.8 and $40 \mathrm{~cm}$; mesh sizes from 0.9 to $10 \mathrm{~cm}$; and, z-distances between 1 and $73 \mathrm{~cm}$. See Guadayol et al. 
(2009b) for additional equations describing $\varepsilon$ within the grid path as well as variations for constant and sinusoidal grid motion.

\section{Couette cylinders}

In Couette cylinders, the rotational rate and shears can be easily converted to $\varepsilon$ (Thomas and Gibson, 1990b):

$\varepsilon=v\left(\frac{R \cdot D \cdot \pi}{60 \cdot G}\right)^{2}$

where $v=$ kinematic viscosity $\left(\mathrm{m}^{2} / \mathrm{s}\right), R=$ rotational rate in revolutions per minute $(\mathrm{rpm}), D=$ the diameter of the outer cylinder (m), and $G=$ the gap width (m). Note that the contents of the parentheses $(R D \pi / 60 G)$ correspond to the value for strain $(\gamma)$ in radians per second (rads/s).

\section{Conclusion}

We have observed that experiments involving phytoplankton-turbulence interactions take many forms often dictated by budget, access to facilities and/or the background experience of the researchers themselves. This paper aimed to review the various techniques used to both generate turbulence and quantify the turbulence produced.

With regards to the method of turbulence generation, most (31\%) previous cosm work has been carried out using oscillating grids (as compared to aeration, Couette cylinders and shaker tables); it is our recommendation that future studies continue to make use of this method due to operational advantages and a robust set of literature and historical data for results comparison. Oscillating grids are simple, effective, and inexpensive, with 29 out of 32 studies reviewed quantifying the turbulence produced. The grids themselves can generate near-isotropic turbulence across a wide range of scales. A grid setup is relatively lowcost to implement or retrofit to existing facilities using basic variable-speed motors. Furthermore, grid setups can easily be applied to large tanks $\left(>1 \mathrm{~m}^{3}\right)$ to enable capturing a wider range of turbulence length scales. It is important that a mesh barrier (e.g. MacKenzie and Kiørboe (1995) be placed between the grid area and the organism to not only reduce the risk of mechanical damage but also to create a refuge region that allows the organisms respite from the turbulence. Similarly, it is important the grids are programmed accordingly to oscillate at a frequency that provides further temporal respite from maximum turbulence. Similarly, the cosm itself and the stroke length over which the grid should oscillate should be on the order of at least one metre to properly reflect the natural length scales of vertical overturns.

With regards to our recommendation for quantification methods, Acoustic Doppler velocimeters (ADV) are both the most commonly used as well as the least complex and inexpensive of the methodologies. However, we do recognise that using an ADV within an environment with an oscillating grid does provide some logistical challenges to overcome.

Phytoplankton-turbulence interactions are complex (Fig. 1); however, studies of this nature are a critical tool for helping us to better understand not only how the aquatic environment functions but also how it will respond as climate change continues to alter turbulent regimes across the planet (Hallegraeff, 2010; Hinder et al., 2012). Worryingly, the number of publications of this nature has been declining in recent years (Fig. 6). Only by 1) standardising future phytoplankton-turbulence experiments and 2) promoting more interdisciplinary collaboration between fluid dynamicists and aquatic ecologists will we be able to better understand the subtle, yet dominant and complex, ways that turbulence influences the microscopic lives of phytoplankton.

Open Access This article is licensed under a Creative Commons Attribution 4.0 International License, which permits use, sharing, adaptation, distribution and reproduction in any medium or format, as long as you give appropriate credit to the original author(s) and the source, provide a link to the Creative Commons licence, and indicate if changes were made. The images or other third party material in this article are included in the article's Creative Commons licence, unless indicated otherwise in a credit line to the material. If material is not included in the article's Creative Commons licence and your intended use is not permitted by statutory regulation or exceeds the permitted use, you will need to obtain permission directly from the copyright holder. To view a copy of this licence, visit http://creativecommons.org/licenses/by/4.0/.

\section{References}

Aguilera, J., C. Jiménez, J. M. Rodríguez-Maroto \& F. X. Niell, 1994. Influence of subsidiary energy on growth of 
Dunaliella viridis Teodoresco: the role of extra energy in algal growth. Journal of Applied Phycology 6(3): 323-330.

Alcaraz, M., E. Saiz, C. Marrasé \& D. Vaqué, 1988. Effects of turbulence on the development of phytoplankton biomass and copepod populations in marine microcosms. Marine Ecology Progress Series 49: 117-125.

Alexander, A. C., E. Luiker, M. Finley \& J. M. Culp, 2016. Chapter 8 - Mesocosm and Field Toxicity Testing in the Marine Context. In Blasco, J., P. M. Chapman, O. Campana \& M. Hampel (eds) Marine Ecotoxicology. Academic Press, New York: 239-256.

Alldredge, A. L., T. C. Granata, C. C. Gotschalk \& T. D. Dickey, 1990. The physical strength of marine snow and its implications for particle disaggregation in the ocean. Limnology and Oceanography 35(7): 1415-1428.

Arin, L., C. Marrasé, M. Maar, F. Peters, M. M. Sala \& M. Alcaraz, 2002. Combined effects of nutrients and smallscale turbulence in a microcosm experiment. I. Dynamics and size distribution of osmotrophic plankton. Aquatic Microbial Ecology 29(1): 51-61.

Bakus, G. J., 1973. Some effects of turbulence and light on competition between two species of phytoplankton. Investigación Pesquera 37: 87-100.

Båmstedt, U. \& H. Larsson, 2018. An indoor pelagic mesocosm facility to simulate multiple water-column characteristics. International Aquatic Research 10(1): 13-29.

Banse, K., 1991. Rates of phytoplankton cell division in the field and in iron enrichment experiments. Limnology and Oceanography 36(8): 1886-1898.

Beauvais, S., M. L. Pedrotti, J. Egge, K. Iversen \& C. Marrasé, 2006. Effects of turbulence on TEP dynamics under contrasting nutrient conditions: implications for aggregation and sedimentation processes. Marine Ecology Progress Series 323: 47-57.

Behm, J. E., B. R. Waite, S. T. Hsieh \& M. R. Helmus, 2018. Benefits and limitations of three-dimensional printing technology for ecological research. BioMed Central Ecology 18(1): 32-33.

Berdalet, E., 1992. Effects of turbulence on the marine dinoflagellate Gymnodinium nelsonii. Journal of Phycology 28(3): 267-272.

Berdalet, E. \& M. Estrada, 1993. Effects of turbulence on several phytoplankton species. In Smayda, T. J. \& Y. Shimizu (eds) Toxic phytoplankton blooms in the sea. Developments in Marine Biology, vol 3. Elsevier, Amsterdam: 737-740.

Berdalet, E., F. Peters, V. L. Koumandou, C. Roldán, Ò. Guadayol \& M. Estrada, 2007. Species-specific physiological response of dinoflagellates to quantified small-scale turbulence. Journal of Phycology 43(5): 965-977.

Bergkvist, J., I. Klawonn, M. J. Whitehouse, G. Lavik, V. Brüchert \& H. Ploug, 2018. Turbulence simultaneously stimulates small- and large-scale $\mathrm{CO} 2$ sequestration by chain-forming diatoms in the sea. Nature Communications 9(1): 3046.

Bienfang, P. K., P. J. Harrison \& L. M. Quarmby, 1982. Sinking rate response to depletion of nitrate, phosphate and silicate in four marine diatoms. Marine Biology 67(3): 295-302.

Bluteau, C. E., N. L. Jones \& G. N. Ivey, 2011. Estimating turbulent kinetic energy dissipation using the inertial subrange method in environmental flows. Limnology and Oceanography: Methods 9(7): 302-321.

Chen, D., K. Muda, K. Jones, J. Leftly \& P. Stansby, 1998. Effect of shear on growth and motility of Alexandrium minutum Halim, a red-tide dinoflagellate. In Reguera, B., J. Blanco, M. L. Fernández \& T. Wyatt (eds), Harmful algae. Xunta de Galicia and Intergovernmental Oceanographic Commision of UNESCO, Vigo: 352-355.

Coble, P. G., 2007. Marine optical biogeochemistry: the chemistry of ocean color. Chemical Reviews 107(2): 402-418.

Couette, M., 1890. Distinction de deux régimes dans le mouvement des fluides. Journal de Physique Théorique et Appliquée 9(1): 414-424.

Cózar, A. \& F. Echevarría, 2005. Size structure of the planktonic community in microcosms with different levels of turbulence. Scientia Marina 69(2): 187-197.

Crimaldi, J. P., 2008. Planar laser induced fluorescence in aqueous flows. Experiments in Fluids 44(6): 851-863.

Crossland, N. O. \& T. W. La Point, 1992. The design of mesocosm experiments. Environmental Toxicology and Chemistry 11(1): 1-4.

Davis, E. A., J. Dedrick, C. S. French, H. W. Milner, J. Myers, J. H. C. Smith \& H. A. Spoehr, 1953. Laboratory experiments on Chlorella culture at the Carnegie Institution of Washington department of plant biology. In Burlew, J. S. (ed.), Algal culture from laboratory to pilot plant, 5th ed. Carnegie Institution of Washington, Washington DC: 105-153.

Dawidowicz, P., 1990. The effect of Daphnia on filament length of blue-green algae. Hydrobiologia 191(1): 265-268.

Delaney, M. P., 2003. Effects of temperature and turbulence on the predator-prey interactions between a heterotrophic flagellate and a marine bacterium. Microbial ecology 45(3): 218-225.

Dempsey, H. P., 1982. The effects of turbulence on three algae: Skeletonema costatum, Gonyaulax tamarensis. Heterocapsa triquentra, Massachusetts Institute of Technology.

Dolan, J. R., N. Sall, A. Metcalfe \& B. Gasser, 2003. Effects of turbulence on the feeding and growth of a marine oligotrich ciliate. Aquatic Microbial Ecology 31(2): 183-192.

Donaghay, P. L. \& E. Klos, 1985. Physical, chemical and biological responses to simulated wind and tidal mixing in experimental marine ecosystems. Marine Ecology Progress Series 26(1/2): 35-45.

Eder, A., B. Durst \& M. Jordan, 2001. Laser-Doppler velocimetry: principle and application to turbulence measurements. In Mayinger, F. \& O. Feldmann (eds), Optical measurements: techniques and applications. Springer, Berlin: 117-138.

Eppley, R. W., P. Koeller \& G. T. Wallace, 1978. Stirring influences the phytoplankton species composition within enclosed columns of coastal sea water. Journal of Experimental Marine Biology and Ecology 32(3): 219-239.

Escaravage, V., L. P. M. J. Wetsteyn, T. C. Prins, A. J. Pouwer, A. de Kruyff, M. Vink-Lievaart, C. M. van der Voom, J. C. H. Peeters \& A. C. Smaal, 1997. The impact of marine eutrophication on phytoplankton, zooplankton and benthic suspension feeders. Stratification in mesocosms, a pilot experiment. Ministerie van Verkeer en Waterstaat, The Netherlands, 52. 
Estrada, M., M. Alcaraz \& C. Marrasé, 1987. Effects of turbulence on the composition of phytoplankton assemblages in marine microcosms. Marine Ecology Progress Series 38: 267-281.

Fogg, G. E. \& Than-Tun, 1960. Interrelations of photosynthesis and assimilation of elementary nitrogen in a blue-green alga. Proceedings of the Royal Society of London Series B Biological Sciences 153(950): 111-127.

Fraisse, S., M. Bormans \& Y. Lagadeuc, 2015. Turbulence effects on phytoplankton morphofunctional traits selection. Limnology and Oceanography 60(3): 872-884.

Franks, P. J. S., 2001. Turbulence avoidance: an alternate explanation of turbulence-enhanced ingestion rates in the field. Limnology and Oceanography 46(4): 959-963.

Franks, P. J. S. \& J. S. Jaffe, 2008. Microscale variability in the distributions of large fluorescent particles observed in situ with a planar laser imaging fluorometer. Journal of Marine Systems 69(3): 254-270.

Fuchs, H. L. \& G. P. Gerbi, 2016. Seascape-level variation in turbulence- and wave-generated hydrodynamic signals experienced by plankton. Progress in Oceanography 141: 109-129.

Garrison, H. S. \& K. W. Tang, 2014. Effects of episodic turbulence on diatom mortality and physiology, with a protocol for the use of Evans Blue stain for live-dead determinations. Hydrobiologia 738(1): 155-170.

Gibson, C. H. \& W. H. Thomas, 1995. Effects of turbulence intermittency on growth inhibition of a red tide dinoflagellate, Gonyaulax polyedra Stein. Journal of Geophysical Research: Oceans 100(C12): 24841-24846.

Gonzalez-Fernandez, C., J. Toullec, C. Lambert, N. Le Goic, M. Seoane, B. Moriceau, A. Huvet, M. Berchel, D. Vincent, L. Courcot, P. Soudant \& I. Paul-Pont, 2019. Do transparent exopolymeric particles (TEP) affect the toxicity of nanoplastics on Chaetoceros neogracile? Environmental Pollution 250: 873-882.

Grobbelaar, J. U., 1989. Do light/dark cycles of medium frequency enhance phytoplankton productivity? Journal of Applied Phycology 1(4): 333-340.

Guadayol, O., C. Marrasé, F. Peters, E. Berdalet, N. Roldá \& A. Sabata, 2009a. Responses of coastal osmotrophic planktonic communities to simulated events of turbulence and nutrient load throughout a year. Journal of Plankton Research 31(6): 583-600.

Guadayol, Ò., F. Peters, J. E. Stiansen, C. Marrasé \& A. Lohrmann, 2009b. Evaluation of oscillating grids and orbital shakers as means to generate isotropic and homogeneous small-scale turbulence in laboratory enclosures commonly used in plankton studies. Limnology and Oceanography: Methods 7(): 287IOP Publishing, 303.

Guasto, J. S., R. Rusconi \& R. Stocker, 2012. Fluid mechanics of planktonic microorganisms. Annual Review of Fluid Mechanics 44: 373-400.

Hallegraeff, G. M., 2010. Ocean climate change, phytoplankton community responses, and harmful algal blooms: a formidable predictive challenge. Journal of Phycology 46(2): 220-235.

Havskum, H., 2003. Effects of small-scale turbulence on interactions between the heterotrophic dinoflagellate Oxyrrhis marina and its prey. Isochrysis sp. Ophelia 57(3): 125-135.
Havskum, H. \& P. J. Hansen, 2006. Net growth of the bloomforming dinoflagellate Heterocapsa triquetra and $\mathrm{pH}$ : why turbulence matters. Aquatic Microbial Ecology 42(1): 55-62.

Havskum, H., P. J. Hansen \& E. Berdalet, 2005. Effect of turbulence on sedimentation and net population growth of the dinoflagellate Ceratium tripos and interactions with its predator. Fragilidium subglobosum. Limnology and Oceanography 50(5): 1543-1551.

Hellung-Larsen, P. \& I. Lyhne, 1992. Effect of shaking on the growth of diluted cultures of Tetrahymena. The Journal of Protozoology 39(2): 345-349.

Hinder, S. L., G. C. Hays, M. Edwards, E. C. Roberts, A. W. Walne \& M. B. Gravenor, 2012. Changes in marine dinoflagellate and diatom abundance under climate change. Nature Climate Change 2(4): 271-275.

Hondzo, M. M., A. Kapur \& C. A. Lembi, 1997. The effect of small-scale fluid motion on the green alga Scenedesmus quadricauda. Hydrobiologia 364(2): 225-235.

Howarth, R. W., T. Butler, K. Lunde, D. Swaney \& C. R. Chu, 1993. Turbulence and planktonic nitrogen fixation: a mesocosm experiment. Limnology and Oceanography 38(8): 1696-1711

Hoyer, K., M. Holzner, B. Lüthi, M. Guala, A. Liberzon \& W. Kinzelbach, 2005. 3D scanning particle tracking velocimetry. Experiments in Fluids 39(5): 923.

Huisman, J., P. Van Oostveen \& F. J. Weissing, 1999. Critical depth and critical turbulence: two different mechanisms for the development of phytoplankton blooms. Limnology and Oceanography 44(7): 1781-1787.

Iversen, K. R., R. Primicerio, A. Larsen, J. K. Egge, F. Peters, Ó. Guadayol, A. Jacobsen, H. Havskum \& C. Marrasé, 2009. Effects of small-scale turbulence on lower trophic levels under different nutrient conditions. Journal of Plankton Research 32(2): 197-208.

Juhl, A. R. \& M. I. Latz, 2002. Mechanisms of fluid shearinduced inhibition of population growth in a red-tide dinoflagellate. Journal of Phycology 38(4): 683-694.

Juhl, A. R., V. Velazquez \& M. I. Latz, 2000. Effect of growth conditions on flow-induced inhibition of population growth of a red-tide dinoflagellate. Limnology and Oceanography 45(4): 905-915.

Juhl, A. R., V. L. Trainer \& M. I. Latz, 2001. Effect of fluid shear and irradiance on population growth and cellular toxin content of the dinoflagellate Alexandrium fundyense. Limnology and Oceanography 46(4): 758-764.

Kaku, V. J., M. C. Boufadel \& A. D. Venosa, 2006. Evaluation of mixing energy in laboratory flasks used for dispersant effectiveness testing. Journal of Environmental Engineering 132(1): 93-101.

Kangas, P. C. \& W. H. Adey, 2008. Mesocosm Management. In Jørgensen, S. E. \& B. D. Fath (eds), Encyclopedia of Ecology. Academic Press, Oxford: 2308-2313.

Karp-Boss, L., E. Boss \& P. A. Jumars, 2000. Motion of dinoflagellates in a simple shear flow. Limnology and Oceanography 45(7): 1594-1602.

Karp-Boss, L. \& P. A. Jumars, 1998. Motion of diatom chains in steady shear flow. Limnology and Oceanography 43(8): 1767-1773.

Katija, K., 2012. Biogenic inputs to ocean mixing. The Journal of Experimental Biology 215(6): 1040-1049. 
Kilham, P., 1971. A hypothesis concerning silica and the freshwater planktonic diatoms. Limnology and Oceanography 16(1): 10-18.

Kiørboe, T., 1993. Turbulence, phytoplankton cell size, and the structure of pelagic food webs. Advances in Marine Biology 29: 1-72.

Kiørboe, T., K. P. Andersen \& H. G. Dam, 1990. Coagulation efficiency and aggregate formation in marine phytoplankton. Marine Biology 107(2): 235-245.

Kirke, B. K., Pumping downwards to prevent algal blooms. In: IWA 2nd World Water Congress, Berlin, 2001.

Köhler, J., 1997. Measurement of in situ growth rates of phytoplankton under conditions of simulated turbulence. Journal of Plankton Research 19(7): 849-862.

Kromkamp, J., F. Schanz, M. Rijkeboer, E. Berdalet, B. Kim \& H. J. Gons, 1992. Influence of the mixing regime on algal photosynthetic performance in laboratory scale enclosures. Hydrobiologia 238(1): 111-118.

Latz, M. I. \& J. Rohr, 1999. Luminescent response of the red tide dinoflagellate Lingulodinium polyedrum to laminar and turbulent flow. Limnology and Oceanography 44(6): 1423-1435.

Latz, M. I., J. F. Case \& R. L. Gran, 1994. Excitation of bioluminescence by laminar fluid shear associated with simple Couette flow. Limnology and Oceanography 39(6): 1424-1439.

Latz, M. I., J. C. Nauen \& J. Rohr, 2004. Bioluminescence response of four species of dinoflagellates to fully developed pipe flow. Journal of Plankton Research 26(12): 1529-1546.

Latz, M. I., J. Allen, S. Sarkar \& J. Rohr, 2009. Effect of fully characterized unsteady flow on population growth of the dinoflagellate Lingulodinium polyedrum. Limnology and Oceanography 54(4): 1243-1256.

Laws, E. A., K. L. Terry, J. Wickman \& M. S. Chalup, 1983. A simple algal production system designed to utilize the flashing light effect. Biotechnology and Bioengineering 25(10): 2319-2335.

Lazier, J. R. N. \& K. H. Mann, 1989. Turbulence and the diffusive layers around small organisms. Deep Sea Research Part A Oceanographic Research Papers 36(11): 1721-1733.

Leeuw, T., E. S. Boss \& D. L. Wright, 2013. In situ measurements of phytoplankton fluorescence using low cost electronics. Sensors 13(6): 7872-7883.

Leterme, S. C., I. Kesaulya, J. G. Mitchell \& L. Seuront, 2008. The impact of turbulence and phytoplankton dynamics on foam formation, seawater viscosity and chlorophyll concentrations in the eastern English Channel. Oceanologia 50(2): 167-182.

Linares, M. C., 2015. Effects of turbulence and laser exposure on phytoplankton behavior. Universitat Politecnica de Catalunya.

Liu, F., L. Zeng, Y. H. Wu, B. Baoligao \& X. Chen, 2017. Vertical distribution of motile phytoplankton in density currents. In: Li, P. (ed) 3rd International Conference on Water Resource and Environment (WRE 2017), Qingdao, China, 26-29 June 2017. IOP Conference Series: Earth and Environmental Science, vol 82. IOP Publishing, Bristol, p. 012073 .
Llaveria, G., E. Garcés, O. N. Ross, R. I. Figueroa, N. Sampedro \& E. Berdalet, 2010. Small-scale turbulence can reduce parasite infectivity to dinoflagellates. Marine Ecology Progress Series 412: 45-56.

Lohrmann, A., R. Cabrera, G. Gelfenbaum \& J. Haines, 1995. Direct measurements of Reynolds stress with an acoustic Doppler velocimeter. In: Anderson, S.P., G.F. Appell \& A. J. Williams III (eds) Proceedings of the IEEE Fifth Working Conference on Current Measurement, St. Petersburg, FL, USA, 7-9 Feb 1995. IEEE, pp. 205-210.

Long, J. D., G. W. Smalley, T. Barsby, J. T. Anderson \& M. E. Hay, 2007. Chemical cues induce consumer-specific defenses in a bloom-forming marine phytoplankton. Proceedings of the National Academy of Sciences 104(25): 10512-10517.

Lürling, M., 1998. Effect of grazing-associated infochemicals on growth and morphological development in Scenedesmus acutus (Chlorophyceae). Journal of Phycology 34(4): 578-586.

Maar, M., L. Arin, R. Simó, M.-M. Sala, F. Peters \& C. Marrasé, 2002. Combined effects of nutrients and small-scale turbulence in a microcosm experiment. II. Dynamics of organic matter and phosphorus. Aquatic Microbial Ecology 29(1): 63-72.

MacKenzie, B. R. \& T. Kiørboe, 1995. Encounter rates and swimming behavior of pause-travel and cruise larval fish predators in calm and turbulent laboratory environments. Limnology and Oceanography 40(7): 1278-1289.

Margalef, R., 1997. Turbulence and marine life. In: Marrasé, C., E. Saiz \& J. M. Redondo (eds) Scientia Marina: Lectures on plankton and turbulence. Vol 61 (SUPPL.1), 109-123.

Marrasé, C., J. H. Costello, T. Granata \& J. R. Strickler, 1990. Grazing in a turbulent environment: energy dissipation, encounter rates, and efficacy of feeding currents in Centropages hamatus. Proceedings of the National Academy of Sciences of the United States of America 87(5): 1653-1657.

Martin, J. H. \& R. Michael Gordon, 1988. Northeast Pacific iron distributions in relation to phytoplankton productivity. Deep Sea Research Part A Oceanographic Research Papers 35(2): 177-196.

Martínez, R. A., A. Calbet \& E. Saiz, 2017. Effects of smallscale turbulence on growth and grazing of marine microzooplankton. Aquatic Sciences 80(1).

Matheson, F. E., 2008. Microcosms. In Jørgensen, S. E. \& B. D. Fath (eds), Encyclopedia of Ecology. Academic Press, Oxford: 2393-2397.

Metcalfe, A. M., T. J. Pedley \& T. F. Thingstad, 2004. Incorporating turbulence into a plankton foodweb model. Journal of Marine Systems 49(1-4): 105-122.

Moisander, P. H., J. L. Hench, K. Kononen \& H. W. Paerl, 2002. Small-scale shear effects on heterocystous cyanobacteria. Limnology and Oceanography 47(1): 108-119.

Musielak, M. M., L. E. E. Karp-Boss, P. A. Jumars \& L. J. Fauci, 2009. Nutrient transport and acquisition by diatom chains in a moving fluid. Journal of Fluid Mechanics 638: 401-421.

Naselli-Flores, L., T. Zohary \& J. Padisák, 2020. Life in suspension and its impact on phytoplankton morphology: an homage to Colin S. Reynolds. Hydrobiologia 848: 7-30 (2021). 
Nedbal, L., V. Tichý, F. Xiong \& J. U. Grobbelaar, 1996. Microscopic green algae and cyanobacteria in high-frequency intermittent light. Journal of Applied Phycology 8(4): 325-333.

Nejstgaard, J. C., L.-J. Naustvoll \& A. Sazhin, 2001a. Correcting for underestimation of microzooplankton grazing in bottle incubation experiments with mesozooplankton. Marine Ecology Progress Series 221: 59-75.

Nejstgaard, J., B. H. Hygum, L.-J. Naustvoll \& U. Båmstedt, 2001b. Zooplankton growth, diet and reproductive success compared in simultaneous diatom- and flagellate-microzooplankton-dominated plankton blooms. Marine Ecology Progress Series 221: 77-91.

Nerheim, S., J. E. Stiansen \& H. Svendsen, 2002. Grid-generated turbulence in a mesocosm experiment. Hydrobiologia 484: 61-73.

Odum, E. P., 1984. The Mesocosm. BioScience 34(9): 558-562.

Okubo, A., 1976. Remarks on the use of 'diffusion diagrams' in modeling scale-dependent diffusion. Deep Sea Research and Oceanographic Abstracts 23(12): 1213-1214.

Oviatt, C. A., 1981. Effects of different mixing schedules on phytoplankton, zooplankton and nutrients in marine microcosms. Marine Ecology Progress Series 4: 57-67.

Paczkowska, J., O. F. Rowe, L. Schlüter, C. Legrand, B. Karlson \& A. Andersson, 2017. Allochthonous matter: an important factor shaping the phytoplankton community in the Baltic Sea. Journal of Plankton Research 39(1): 23-34.

Padisák, J., É. Soróczki-Pintér \& Z. Rezner, 2003. Sinking properties of some phytoplankton shapes and the relation of form resistance to morphological diversity of plankton an experimental study. Hydrobiolgia 500: 243-257.

Pahlow, M., U. Riebesell \& D. A. Wolf-Gladrow, 1997. Impact of cell shape and chain formation on nutrient acquisition by marine diatoms. Limnology and Oceanography 42(8): 1660-1672.

Pannard, A., M. Bormans, S. Lefebvre, P. Claquin \& Y. Lagadeuc, 2007. Phytoplankton size distribution and community structure: influence of nutrient input and sedimentary loss. Journal of Plankton Research 29(7): 583-598.

Parsons, T. R., P. J. Harrison \& R. Waters, 1978. An experimental simulation of changes in diatom and flagellate blooms. Journal of Experimental Marine Biology and Ecology 32(3): 285-294.

Pasciak, W. J. \& J. Gavis, 1975. Transport limited nutrient uptake rates in Ditylum brightwellii. Limnology and Oceanography 20(4): 604-617.

Peters, F. \& T. Gross, 1994. Increased grazing rates of microplankton in response to small-scale turbulence. Marine Ecology Progress Series 115(3): 299-308.

Peters, F. \& J. M. Redondo, 1997. Turbulence generation and measurement: application to studies on plankton. In Marrasé, C., E. Saiz \& J. M. Redondo (eds) Scientia Marina: Lectures on plankton and turbulence, vol. 61. International Centre for Coastal Resources, Barcelona: 205-228.

Peters, F. \& C. Marrasé, 2000. Effects of turbulence on plankton: an overview of experimental evidence and some theoretical considerations. Marine Ecology Progress Series 205: 291-306.

Peters, F., J. W. Choi \& T. Gross, 1996. Paraphysomonas imperforata (Protista, Chrysomonadida) under different turbulence levels: feeding, physiology and energetics. Marine Ecology Progress Series 134: 235-245.

Peters, F., C. Marrasé, H. Havskum, F. Rassoulzadegan, J. Dolan, M. Alcaraz \& J. M. Gasol, 2002. Turbulence and the microbial food web: effects on bacterial losses to predation and on community structure. Journal of Plankton Research 24(4): 321-331.

Peters, F., L. Arin, C. Marrasé, E. Berdalet \& M. M. Sala, 2006. Effects of small-scale turbulence on the growth of two diatoms of different size in a phosphorus-limited medium. In: Peters, F. \& C. Hannah (eds) Workshop on Future Directions in Modelling Physical-Biological Interactions (WKFDPBI), Barcelona, Catalunya, Spain, 7-9 March 2004. Journal of Marine Systems 61(3-4): 134-148.

Petersen, J. E., L. P. Sanford \& W. M. Kemp, 1998. Coastal plankton responses to turbulent mixing in experimental ecosystems. Marine Ecology Progress Series 171: 23-41.

Pollingher, U. \& E. Zemel, 1981. In situ and experimental evidence of the influence of turbulence on cell division processes of Peridinium cinctum forma westii (Lemm.) Lefèvre. British Phycological Journal 16(3): 281-287.

Prairie, J. C., K. R. Sutherland, K. J. Nickols \& A. M. Kaltenberg, 2012. Biophysical interactions in the plankton: a cross-scale review. Limnology and Oceanography: Fluids and Environments 2(1): 121-145.

Pringle, J. M., 2007. Turbulence avoidance and the wind-driven transport of plankton in the surface Ekman layer. Continental Shelf Research 27(5): 670-678.

Raffel, M., C. E. Willert, F. Scarano, C. J. Kähler, S. T. Wereley \& J. Kompenhans, 2018. Particle image velocimetry: a practical guide. Springer, Berlin.

Regel, R. H., J. D. Brookes, G. G. Ganf \& R. W. Griffiths, 2004. The influence of experimentally generated turbulence on the Mash01 unicellular Microcystis aeruginosa strain. Hydrobiologia 517(1): 107-120.

Reynolds, C. S., 2009. Biological-Physical Interactions. In Likens, G. E. (ed.), Encyclopedia of Inland Waters. Academic Press, Oxford: 515-521.

Richmond, A. \& A. Vonshak, 1978. Spirulina culture in Israel. Archiv für Hydrobiologie - Beihefte Ergebnisse der Limnologie 11: 274-280.

Rijkeboer, M., F. de Bles \& H. J. Gons, 1990. Laboratory scale enclosure: concept, construction and operation. Journal of Plankton Research 12(1): 231-244.

Rohr, J., J. Losee \& J. Hoyt, 1990. Stimulation of bioluminescence by turbulent pipe flow. Deep Sea Research Part A, Oceanographic Research Papers 37(10): 1639-1646.

Rohr, J., J. Allen, J. Losee \& M. I. Latz, 1997. The use of bioluminescence as a flow diagnostic. Physics Letters A 228(6): 408-416.

Rohr, J., M. Hyman, S. Fallon \& M. I. Latz, 2002. Bioluminescence flow visualization in the ocean: an initial strategy based on laboratory experiments. Deep Sea Research Part I: Oceanographic Research Papers 49(11): 2009-2033.

Ross, O. N. \& J. Sharples, 2007. Phytoplankton motility and the competition for nutrients in the thermocline. Marine Ecology Progress Series 347: 21-38.

Ross, O. N. \& J. Sharples, 2008. Swimming for survival: a role of phytoplankton motility in a stratified turbulent environment. Journal of Marine Systems 70(3-4): 248-262. 
Rothschild, B. J. \& T. R. Osborn, 1988. Small-scale turbulence and plankton contact rates. Journal of Plankton Research 10(3): 465-474.

Saiz, E. \& M. Alcaraz, 1992. Free-swimming behaviour of Acartia clausi (Copepoda: calanoida) under turbulent water movement. Marine Ecology Progress Series 80(2-3): 229-236.

Saiz, E. \& T. Kiørboe, 1995. Predatory and suspension feeding of the copepod Acartia tonsa in turbulent environments. Oceanographic Literature Review 43(1): 59.

Sanford, L. P., 1997. Turbulent mixing in experimental ecosystem studies. Marine Ecology Progress Series 161: 265-293.

Santschi, P. H., 1985. The MERL mesocosm approach for studying sediment-water interactions and ecotoxicology. Environmental Technology Letters 6(1-11): 335-350.

Sato, T., D. Yamada \& S. Hirabayashi, 2010. Development of virtual photobioreactor for microalgae culture considering turbulent flow and flashing light effect. Energy Conversion and Management 51(6): 1196-1201.

Savidge, G., 1981. Studies of the effects of small-scale turbulence on phytoplankton. Journal of the Marine Biological Association of the United Kingdom 61(2): 477-488.

Scarano, F., 2012. Tomographic PIV: principles and practice. Measurement Science and Technology 24(1): 012001.

Schapira, M., L. Seuront \& V. Gentilhomme, 2006. Effects of small-scale turbulence on Phaeocystis globosa (Prymnesiophyceae) growth and life cycle. Journal of Experimental Marine Biology and Ecology 335(1): 27-38.

Schöne, H., 1970. Untersuchungen zur ökologischen Bedeutung des Seegangs für das Plankton mit besonderer Berücksichtigung mariner Kieselalgen. Internationale Revue der gesamten Hydrobiologie und Hydrographie 55(4): 595-677.

Schwartz, E. R., R. X. Poulin, N. Mojib \& J. Kubanek, 2016. Chemical ecology of marine plankton. Natural Product Reports 33(7): 843-860.

Sengupta, A., F. Carrara \& R. Stocker, 2017. Phytoplankton can actively diversify their migration strategy in response to turbulent cues. Nature 543: 555-558.

Simoncelli, S., S. J. Thackeray \& D. J. Wain, 2019. Effect of temperature on zooplankton vertical migration velocity. Hydrobiologia 829(1): 143-166.

Smayda, T. J. \& C. S. Reynolds, 2001. Community assembly in marine phytoplankton: application of recent models to harmful dinoflagellate blooms. Journal of Plankton Research 23(5): 447-461.

Smith, B. C. \& A. Persson, 2005. Synchronization of encystment of Scrippsiella lachrymosa (Dinophyta). Journal of Applied Phycology 17(4): 317-321.

Solomon, K. R. \& M. Hanson, 2014. Mesocosms and Microcosms (Aquatic) Encyclopedia of Toxicology: Third Edition. 223-226.

Sonntag, N. C. \& T. R. Parsons, 1979. Mixing an enclosed, $1300 \mathrm{~m}^{3}$ water column: effects on the planktonic food web. Journal of Plankton Research 1(1): 85-102.

Staehr, P. A. \& K. Sand-Jensen, 2006. Seasonal changes in temperature and nutrient control of photosynthesis, respiration and growth of natural phytoplankton communities. Freshwater Biology 51(2): 249-262.
Steele, J. H., D. M. Farmer \& E. W. Henderson, 1977. Circulation and temperature structure in large marine enclosures. Journal of the Fisheries Research Board of Canada 34(8): 1095-1104.

Stoecker, D. K., A. Long, S. E. Suttles \& L. P. Sanford, 2006. Effect of small-scale shear on grazing and growth of the dinoflagellate Pfiesteria piscicida. Harmful Algae 5(4): 407-418.

Stokes, M. D., G. B. Deane, M. I. Latz \& J. Rohr, 2004. Bioluminescence imaging of wave-induced turbulence. Journal of Geophysical Research: Oceans 109(C1): 1-8.

Striebel, M., L. Kirchmaier \& P. Hingsamer, 2013. Different mixing techniques in experimental mesocosms-does mixing affect plankton biomass and community composition? Limnology and Oceanography: Methods 11(4): 176-186.

Sullivan, J. M. \& E. Swift, 2003. The effect of small-scale turbulence on net growth rate and size of ten species of marine dinoflagellates. Journal of Phycology 39: 83-94.

Sullivan, J. M., E. Swift, P. L. Donaghay \& J. E. B. Rines, 2003. Small-scale turbulence affects the division rate and morphology of two red-tide dinoflagellates. Harmful Algae 2(3): 183-199.

Svensen, C., J. K. Egge \& J. E. Stiansen, 2001. Can silicate and turbulence regulate the vertical flux of biogenic matter? A mesocosm study. Marine Ecology Progress Series 217: 67-80.

Sverdrup, H. U., 1953. On conditions for the vernal blooming of phytoplankton. ICES Journal of Marine Science 18(3): 287-295.

Talling, J. F., 1960. Comparative laboratory and field studies of photosynthesis by a marine planktonic diatom. Limnology and Oceanography 5(1): 62-77.

Thomas, W. H. \& C. H. Gibson, 1990a. Effects of small-scale turbulence on microalgae. Journal of Applied Phycology 2(1): 71-77.

Thomas, W. H. \& C. H. Gibson, 1990b. Quantified small-scale turbulence inhibits a red tide dinoflagellate, Gonyaulax polyedra Stein. Deep Sea Research Part A Oceanographic Research Papers 37(10): 1583-1593.

Thomas, W. H. \& C. H. Gibson, 1992. Effects of quantified small-scale turbulence on the dinoflagellate, Gymnodium sanguineum (splendens): contrasts with Gonyaulax (Lingulodinium) polyedra, and the fishery implication. Deep Sea Research Part A Oceanographic Research Papers 39(7): 1429-1437.

Thomas, W. H., D. L. R. Seibert, M. Alden, A. Neori \& P. Eldridge, 1984a. Yields, photosynthetic efficiencies and proximate composition of dense marine microalgal cultures. I. Introduction and Phaeodactylum tricornutum experiments. Biomass 5(3): 181-209.

Thomas, W. H., D. L. R. Seibert, M. Alden, A. Neori \& P. Eldridge, 1984b. Yields, photosynthetic efficiencies and proximate composition of dense marine microalgal cultures. II. Dunaliella primolecta and Tetraselmis suecica experiments. Biomass 5(3): 211-225.

Thomas, W. H., D. L. R. Seibert, M. Alden, A. Neori \& P. Eldridge, 1984c. Yields, photosynthetic efficiencies and proximate composition of dense marine microalgal cultures. III. Isochrysis $\mathrm{sp}$. and Monallantus salina 
experiments and comparative conclusions. Biomass 5(4): 299-316.

Thomas, W. H., C. T. Tynan \& C. H. Gibson, 1997. Turbulencephytoplankton interrelationships. In Round, F. E. \& D. J. Chapman (eds), Progress in Phycological Research, Vol. 12. Biopress Ltd., Bristol: 283-324.

Tropea, C. \& A. L. Yarin, 2007. Springer handbook of experimental fluid mechanics. Springer, Berlin.

Turkoglu, M., 2013. Red tides of the dinoflagellate Noctiluca scintillans associated with eutrophication in the Sea of Marmara (the Dardanelles, Turkey). Oceanologia 55(3): 709-732.

Tuttle, R. C. \& A. R. Loeblich, 1975. An optimal growth medium for the dinoflagellate Crypthecodinium cohnii. Phycologia 14(1): 1-8.

Tynan, C. T., 1993. The effects of small-scale turbulence on dinoflagellates. University of California, San Diego.

Visser, P. M., B. W. Ibelings, M. Bormans \& J. Huisman, 2016. Artificial mixing to control cyanobacterial blooms: a review. Aquatic Ecology 50(3): 423-441.

Waller, W. T. \& H. J. Allen, 2008. Acute and chronic toxicity. In Jørgensen, S. E. \& B. D. Fath (eds), Encyclopedia of Ecology. Academic Press, Oxford: 32-43.

Walsby, A. E., 1971. Pressure relationships of gas vacuoles. Proceedings of the Royal Society of London B 178: 301-326.

Warnaars, T. A., M. Hondzo \& M. A. Carper, 2006. A desktop apparatus for studying interactions between microorganisms and small-scale fluid motion. Hydrobiologia 563(1): 431-443.

Waterhouse, A. F., J. A. MacKinnon, J. D. Nash, M. H. Alford, E. Kunze, H. L. Simmons, K. L. Polzin, L. C. S. Laurent, O. M. Sun, R. Pinkel, L. D. Talley, C. B. Whalen, T. N. Huussen, G. S. Carter, I. Fer, S. Waterman, A. C. N. Garabato, T. B. Sanford \& C. M. Lee, 2014. Global patterns of diapycnal mixing from measurements of the turbulent dissipation rate. Journal of Physical Oceanography 44(7): 1854-1872.
Webster, D. R., A. Brathwaite \& J. Yen, 2004. A novel laboratory apparatus for simulating isotropic oceanic turbulence at low Reynolds number. Limnology and Oceanography: Methods 2: 1-12.

Webster, D. R., P. J. W. Roberts \& L. Ra'ad, 2001. Simultaneous DPTV/PLIF measurements of a turbulent jet. Experiments in Fluids 30(1): 65-72.

White, A. W., 1976. Growth inhibition caused by turbulence in the toxic marine dinoflagellate Gonyaulax excavata. Journal of the Fisheries Research Board of Canada 33(11): 2598-2602.

Wüest, A. \& A. Lorke, 2003. Small-scale hydrodynamics in lakes. Annual Review of fluid mechanics 35(1): 373-412.

$\mathrm{Xu}$, D. \& J. Chen, 2013. Accurate estimate of turbulent dissipation rate using PIV data. Experimental Thermal and Fluid Science 44: 662-672.

Yeung, P. K. K. \& J. T. Y. Wong, 2003. Inhibition of cell proliferation by mechanical agitation involves transient cell cycle arrest at G1 phase in dinoflagellates. Protoplasma 220(3): 173-178.

Yousif, E. \& R. Haddad, 2013. Photodegradation and photostabilization of polymers, especially polystyrene: review. Springerplus 2: 398-399.

Zhou, J., X. Han, B. Qin, C. Casenave \& G. Yang, 2016. Response of zooplankton community to turbulence in large, shallow Lake Taihu: a mesocosm experiment. Fundamental and Applied Limnology/Archiv für Hydrobiologie 187(4): 325-326.

Zirbel, M. J., F. Veron \& M. I. Latz, 2000. The reversible effect of flow on the morphology of Ceratocorys horrida (Peridiniales, Dinophyta). Journal of Phycology 36(1): 46-58.

Publisher's Note Springer Nature remains neutral with regard to jurisdictional claims in published maps and institutional affiliations. 